Article

\title{
Process Parameters Optimization, Characterization, and Application of KOH-Activated Norway Spruce Bark Graphitic Biochars for Efficient Azo Dye Adsorption
}

\author{
Marine Guy ${ }^{1}$, Manon Mathieu ${ }^{2}{ }^{D}$, Ioannis P. Anastopoulos ${ }^{3} \mathbb{D}$, María G. Martínez ${ }^{2} \mathbb{D}$, Frédéric Rousseau ${ }^{1}$, \\ Guilherme L. Dotto ${ }^{4}$, Helinando P. de Oliveira ${ }^{5} \mathbb{D}$, Eder C. Lima ${ }^{6} \mathbb{D}$, Mikael Thyrel ${ }^{7}$, Sylvia H. Larsson ${ }^{7} \mathbb{D}$ \\ and Glaydson S. dos Reis ${ }^{7, *(\mathbb{D})}$
}

check for updates

Citation: Guy, M.; Mathieu, M.; Anastopoulos, I.P.; Martínez, M.G.; Rousseau, F.; Dotto, G.L.; de Oliveira H.P.; Lima, E.C.; Thyrel, M.; Larsson, S.H.; et al. Process Parameters Optimization, Characterization, and Application of $\mathrm{KOH}$-Activated Norway Spruce Bark Graphitic Biochars for Efficient Azo Dye Adsorption. Molecules 2022, 27, 456. https://doi.org/10.3390/molecules 27020456

Academic Editor: João

Valente Nabais

Received: 13 December 2021

Accepted: 6 January 2022

Published: 11 January 2022

Publisher's Note: MDPI stays neutral with regard to jurisdictional claims in published maps and institutional affiliations.

Copyright: (C) 2022 by the authors. Licensee MDPI, Basel, Switzerland. This article is an open access article distributed under the terms and conditions of the Creative Commons Attribution (CC BY) license (https:// creativecommons.org/licenses/by/ $4.0 /)$.
1 National Chemical Engineering Institute in Paris, 75005 Paris, France; marine.guy@etu.chimieparistech.psl.eu (M.G.); frederic.rousseau@chimieparistech.psl.eu (F.R.)

2 Université de Toulouse, Mines Albi, CNRS UMR 5302, Centre RAPSODEE, 81000 Albi, France; manon.mathieu@mines-albi.fr (M.M.); maria.gonzalez_martinez@mines-albi.fr (M.G.M.)

3 Department of Agriculture, University of Ioannina, UoI Kostakii Campus, 47040 Arta, Greece; anastopoulos_ioannis@windowslive.com

4 Chemical Engineering Department, Federal University of Santa Maria (UFSM), Santa Maria 97105-900, RS, Brazil; guilherme_dotto@yahoo.com.br

5 Institute of Materials Science, Federal University of Sao Francisco Valley, Juazeiro 48920-310, BA, Brazil; helinando.oliveira@univasf.edu.br

6 Institute of Chemistry, Federal University of Rio Grande do Sul, Porto Alegre 91501-970, RS, Brazil; profederlima@gmail.com

7 Department of Forest Biomaterials and Technology, Swedish University of Agricultural Sciences, 90183 Umeå, Sweden; mikael.thyrel@slu.se (M.T.); sylvia.larsson@slu.se (S.H.L.)

* Correspondence: glaydson.simoes.dos.reis@slu.se

Abstract: In this work, Norway spruce bark was used as a precursor to prepare activated biochars (BCs) via chemical activation with potassium hydroxide $(\mathrm{KOH})$ as a chemical activator. A BoxBehnken design (BBD) was conducted to evaluate and identify the optimal conditions to reach high specific surface area and high mass yield of BC samples. The studied BC preparation parameters and their levels were as follows: pyrolysis temperature $\left(700,800\right.$, and $\left.900{ }^{\circ} \mathrm{C}\right)$, holding time $(1,2$, and $3 \mathrm{~h}$ ), and ratio of the biomass: chemical activator of 1: 1, 1.5, and 2 . The planned BBD yielded $\mathrm{BC}$ with extremely high SSA values, up to $2209 \mathrm{~m}^{2} \cdot \mathrm{g}^{-1}$. In addition, the BCs were physiochemically characterized, and the results indicated that the BCs exhibited disordered carbon structures and presented a high quantity of O-bearing functional groups on their surfaces, which might improve their adsorption performance towards organic pollutant removal. The BC with the highest SSA value was then employed as an adsorbent to remove Evans blue dye (EB) and colorful effluents. The kinetic study followed a general-order (GO) model, as the most suitable model to describe the experimental data, while the Redlich-Peterson model fitted the equilibrium data better. The EB adsorption capacity was $396.1 \mathrm{mg} \cdot \mathrm{g}^{-1}$. The employment of the BC in the treatment of synthetic effluents, with several dyes and other organic and inorganic compounds, returned a high percentage of removal degree up to $87.7 \%$. Desorption and cyclability tests showed that the biochar can be efficiently regenerated, maintaining an adsorption capacity of $75 \%$ after 4 adsorption-desorption cycles. The results of this work pointed out that Norway spruce bark indeed is a promising precursor for producing biochars with very promising properties.

Keywords: biomass; porous material; Evans blue dye; design of experiments; kinetic and equilibrium study

\section{Introduction}

Carbon-based materials are commonly used in wastewater treatment, soil amendment, gas emission mitigation in the greenhouse, chemical catalysts, and energy storage 
systems [1-3]. Their several remarkable properties, such as highly developed porosity and internal pore structure, elevated specific surface area, and a high degree of surface chemistry, make carbon-based materials efficient candidates for these applications $[3,4]$.

Lately, several carbon-based materials, such as activated carbons, biochars, graphene, carbon nanotubes, and composites of these materials, have been utilized as adsorbents $[1,4,5]$. Activated carbon is the most utilized adsorbent; however, the use of biomass for producing biochar (BC) has led to biochars gaining attention as adsorbents in recent years [1,2].

Biochars are efficient for use in wastewater treatment, primarily due to their highly porous structure and their numerous chemical functionalities [1-4]. In wastewater treatment processes, adsorption is preferred due to characteristics of low implementation costs, relative operation simplicity, and minimal generation of by-products [4-7].

Pyrolysis is the most common process for producing BCs. However, the efficiency of the pyrolysis process in $\mathrm{BC}$ yielding with improved properties is influenced by several factors, such as pyrolysis temperature, holding time, and heating rate [4]. Therefore, the efficient control of these parameters is required to produce BCs with improved textural properties $[1,2,4]$. Additionally, the preparation of $B C$ has another critical step, the activation process, which can be either physical or chemical $[1,2,5,6]$. Chemical activation is performed in the presence of chemical agents. It has the advantage of generally being conducted in a one-step process, using lower activation temperatures, generating BC with higher SSA values, and is a more straightforward process to adjust the porosity of the BCs $[6,7]$. However, some disadvantages of using chemical activation are reported, as the chemical reagents are non-environmentally friendly substances and processes, such as in the acidic washing step, which is applied to remove the remaining chemical activating agent in the carbonized matrix.

Several chemical agents are used to impregnate the raw materials, among which, zinc chloride $\left(\mathrm{ZnCl}_{2}\right)$ and $\mathrm{KOH}$ have been considered the most common ones. The $\mathrm{BC}$ produced with $\mathrm{ZnCl}_{2}$ yields materials with developed mesoporosity, while $\mathrm{KOH}$ activation generally creates microporous and small mesoporous structures with higher SSA [8,9]. Therefore, the characteristics of the $\mathrm{BC}$ can also be adjusted according to the chemical activation employed. Thus, the $\mathrm{KOH}$ activation and its effects on $\mathrm{BC}$ characteristics were explored in this work.

For the production of $\mathrm{BC}$, the isolated and combined influence of variables can play an essential role in the process and may introduce additional difficulties to identify and understand at what condition the BCs with improved properties are produced. For this purpose, statistical designs of experiments have been considered helpful tools that are successfully employed to evaluate the influence of the combined variables in the process. The response surface methodology (RSM) is a valuable statistical tool to optimize different variables utilized to obtain better characteristics of the desired material $[4,10]$. The application of RSM is critical for developing a cost-effective process by elucidating which experimental variables affect $\mathrm{BC} \mathrm{s}^{\prime}$ properties, and how their conditions function $[9,10]$. The RSM aims to reduce the costs and maximize the operation process efficiency over a minimal number of experimental runs [11]. RSM is a proven method that has been widely applied in the literature for the optimization of experimental conditions for BC preparation [10-15].

Azo dyes are organic compounds applied in several domains, such as the food, biomed$\mathrm{ical}$, and textile industries. They are commonly found in the wastewater of these industries, with their high solubility in water, and are dangerous to the environment and human life $[16,17]$. Evans blue (EB) dye, also named Direct Blue 53 dye, belongs to the azo dye class, and its degradation may lead to mutagenicity and carcinogenicity in by-products, especially for the human fetus $[18,19]$. Furthermore, EB has been considered a toxic dye at high dosages, provoking chronic health effects-affecting lung, liver, and intestine function [20]. Therefore, treating effluents loaded with dyes is a vital activity before discharging them into the environment.

The main goal of this study is to determine the effect of pyrolysis conditions on the properties of the spruce bark BCs. In order to optimize these results, an RSM assay was employed, in which variables (pyrolysis temperature, holding time, and the ratio of 
biomass: $\mathrm{KOH}$ ) were studied over two responses: SSA and mass yield. Based on the RSM results, the BC with the highest SSA was chosen and employed to remove Evans blue dye by adsorption process, from which the effect of initial $\mathrm{pH}$, kinetic and equilibrium studies were evaluated. The adsorption-desorption (cyclability) cycles were also studied. Finally, the efficiency of the BC to remove several dyes in synthetic wastewater was evaluated.

\section{Results and Discussion}

\subsection{Process Parameters Optimization for SSA and Yield}

The SSA is an important property of carbon materials due to its massive influence on the desired application, i.e., adsorption performance in removing pollutants from polluted waters $[1,5,14]$. The SSA and mass yield results of each sample are shown in Table 1. Table 1 shows the results of 15 experimental runs, obtained through Box-Behnken design, by evaluating 3 variables (pyrolysis temperature, holding time, and ratio of activating agent) on 2 responses (SSA and Yield).

Table 1. BBD matrix of Box-Behnken surface response methodology.

\begin{tabular}{ccccccc}
\hline $\begin{array}{c}\text { Experiment } \\
\text { Samples }\end{array}$ & $\begin{array}{c}\text { Coded } \\
\text { Samples }\end{array}$ & $\begin{array}{c}\text { Temperature } \\
\left({ }^{\circ} \mathbf{C}\right)\end{array}$ & $\begin{array}{c}\text { Holding } \\
\text { Time } \mathbf{( h )}\end{array}$ & Ratio & $\begin{array}{c}\text { SSA } \\
\left(\mathbf{m}^{2} \cdot \mathbf{g}^{-\mathbf{1})}\right.\end{array}$ & $\begin{array}{c}\text { Mass } \\
\text { Yield (\%) }\end{array}$ \\
\hline $700: 1: 1.5$ & BC1 & 700 & 1 & 1.5 & 346 & 23.6 \\
$900: 1: 1.5$ & BC2 & 900 & 1 & 1.5 & 1355 & 3.0 \\
$700: 3: 1.5$ & BC3 & 700 & 3 & 1.5 & 557 & 21.3 \\
$900: 3: 1.5$ & BC4 & 900 & 3 & 1.5 & 1812 & 3.9 \\
$700: 2: 1$ & BC5 & 700 & 2 & 1 & 726 & 19.3 \\
$900: 2: 1$ & BC6 & 900 & 2 & 1 & 2209 & 11.3 \\
$700: 2: 2$ & BC7 & 700 & 2 & 2 & 274 & 36.8 \\
$900: 2: 2$ & BC8 & 900 & 2 & 2 & 418 & 10.2 \\
$800: 1: 1$ & BC9 & 800 & 1 & 1 & 754 & 12.1 \\
$800: 3: 1$ & BC10 & 800 & 3 & 1 & 1415 & 8.2 \\
$800: 1: 2$ & BC11 & 800 & 1 & 2 & 572 & 11.5 \\
$800: 3: 2$ & BC12 & 800 & 3 & 2 & 1434 & 5.0 \\
$800: 2: 1.5$ & BC13 & 800 & 2 & 1.5 & 2011 & 10.6 \\
$800: 2: 1.5$ & BC14 & 800 & 2 & 1.5 & 2002 & 12.7 \\
$800: 2: 1.5$ & BC15 & 800 & 2 & 1.5 & 1943 & 10.7 \\
\hline
\end{tabular}

The data presented in Table 1 show that the SSA values ranged from 274 to $2209 \mathrm{~m}^{2} . \mathrm{g}^{-1}$, confirming that Norway spruce bark can be considered an efficient precursor for producing $\mathrm{BC}$ with very high SSA values. For instance, Leite et al. [9] produced BCs from avocado seed and reported SSA values in the range of $1122-1584 \mathrm{~m}^{2} \cdot \mathrm{g}^{-1}$. Dos Reis et al. [10] prepared $\mathrm{BC}$ s using sludge sewage as the precursor and reported SSA values up to $679 \mathrm{~m}^{2} \cdot \mathrm{g}^{-1}$.

To further compare our results with the literature, Table 2 presents a short review, containing other studies regarding bio-based activated carbons made with $\mathrm{KOH}$ [21-25]. Yagmur et al. [21] used Oleaster fruits' flesh to make BC with the highest SSA equal to $1816 \mathrm{~m}^{2} \cdot \mathrm{g}^{-1}$ at pyrolysis temperature of $800^{\circ} \mathrm{C}$ and holding time of $1 \mathrm{~h}$, with a biomass: $\mathrm{KOH}$ ratio of 1:3. Guclu et al. [22] employed spent tea leaves to make BC with SSA in the order of $820.7 \mathrm{~m}^{2} \cdot \mathrm{g}^{-1}$ at pyrolysis temperature of $800{ }^{\circ} \mathrm{C}$ and holding time of $1 \mathrm{~h}$, with a biomass: $\mathrm{KOH}$ ratio of 1:1.

According to these results, it can be stated that Norway spruce bark, under the right preparation conditions, is a very suitable precursor for producing highly porous materials. In addition, it is possible to infer that the optimum pyrolysis condition is dependent of the type of the biomass precursor characteristics, and how the pyrolysis process was performed. Therefore, more profound studies are necessary to reliably obtain at which pyrolysis conditions the bio-based carbon materials with improved characteristics are produced. The use of RSM to evaluate and identify which pyrolysis parameters influenced the SSA values is a valuable alternative. Therefore, the following section will evaluate the influence of the pyrolysis conditions on the SSA values of the BCs, using RSM. 
Table 2. Short literature review of ACPB preparation and SSA values.

\begin{tabular}{cccccc}
\hline Biomass & $\begin{array}{c}\text { Temperature } \\
\left({ }^{\circ} \mathbf{C}\right)\end{array}$ & $\begin{array}{c}\text { Holding } \\
\text { Time } \mathbf{( h )}\end{array}$ & Ratio & $\begin{array}{c}\text { SSA } \\
\left(\mathbf{m}^{2} \cdot \mathbf{g}^{-\mathbf{1}} \mathbf{)}\right.\end{array}$ & Ref. \\
\hline Norway spruce bark & 900 & 2 & $1: 1$ & 2209 & This work \\
Oleaster fruits flesh & 800 & 1 & $1: 3$ & 1816 & {$[21]$} \\
Spent tea leaves & 800 & 1 & $1: 1$ & 820.7 & {$[22]$} \\
$\begin{array}{c}\text { Oak wood sawdust } \\
\text { Amazonian nut } \\
\text { shells }\end{array}$ & 800 & 1 & $1: 0.5$ & 1662 & {$[23]$} \\
\hline
\end{tabular}

Parameters Optimization for SSA and Yield of the BC

RSM analysis can be explored to obtain the most influential parameters, for the BC preparation, over the selected responses, SSA, and yield of BCs. Through RSM, it is possible to find the optimized parameters to produce $\mathrm{BC}$ with the high SSA values and mass yield.

The effect of the A (pyrolysis temperature, ${ }^{\circ} \mathrm{C}$ ), B (holding time (min)), and $\mathrm{C}$ (ratio of biomass: $\mathrm{KOH}$ ) on SSA values is shown in Figure 1 (Pareto chart and normal plot). The Pareto chart (see Figure 1a,b) indicates that pyrolysis temperature (A) and the quadratic term of temperature $\left(\mathrm{A}^{2}\right)$ and the quadratic term of ratio $\left(\mathrm{C}^{2}\right)$ were the factors of influence for the SSA. When the response was yielding mass values, the parameters A (temperature), $\mathrm{A}^{2}$ (quadratic of temperature), and A.C (the combination of temperature versus the ratio of activating agent) were the factors that influenced the mass yielding. The normal plot in Figure $1 \mathrm{c}, \mathrm{d}$ ) indicates that temperature influenced the SSA value positively, whereas the terms $\mathrm{A}^{2}$ and $\mathrm{C}^{2}$ had a negative effect on the SSA.
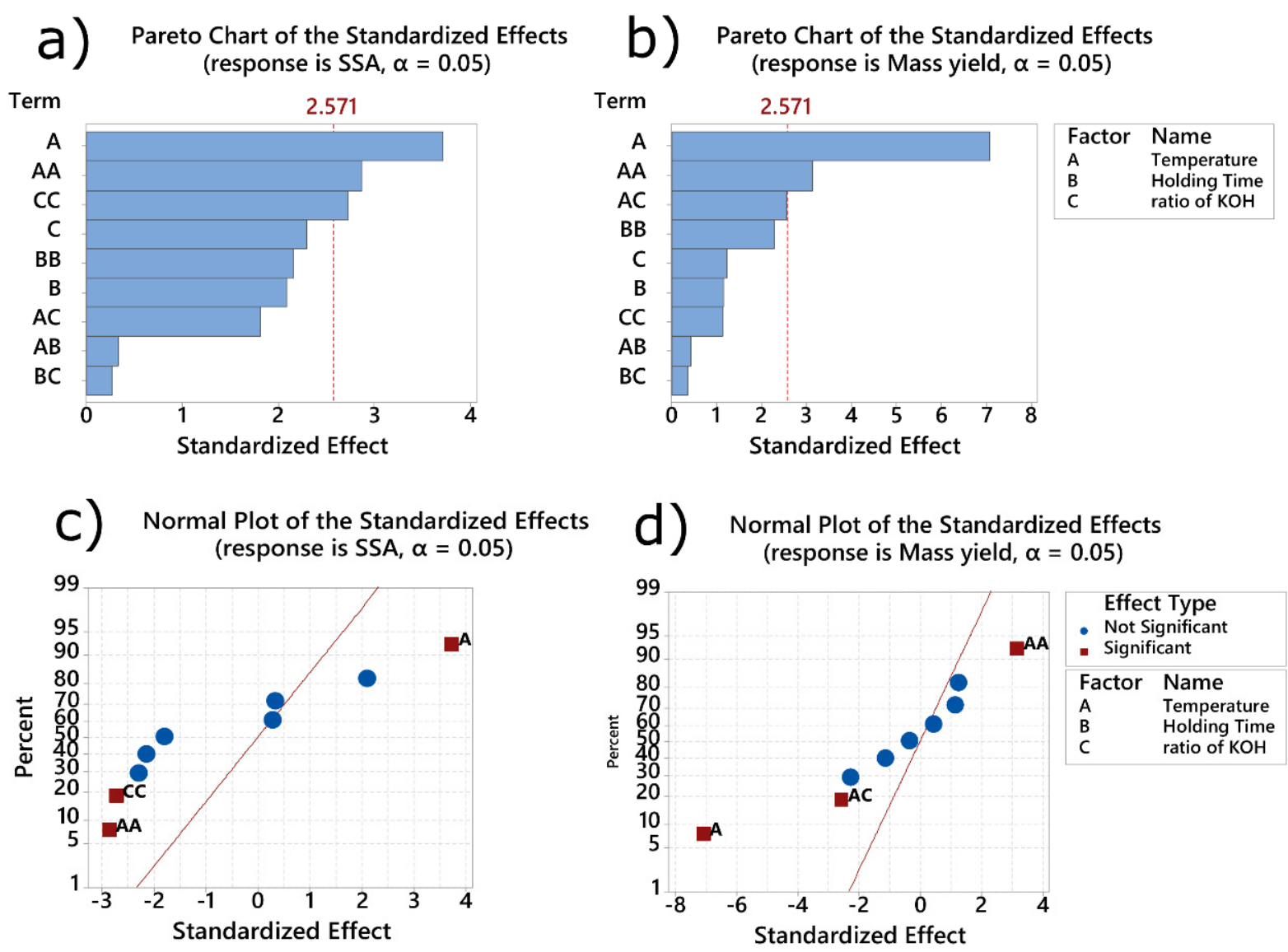

Figure 1. Normal plot for standardized effects: (a) SSA; (b) mass yielding. Pareto chart for: (c) SSA; (d) mass yielding. 
For the response mass yielding, the term $\mathrm{A}^{2}$ had a positive effect on the response; on the other hand, the term A and A.C had a negative effect on the mass yielding. Thus, it is remarkable to show that the statistical response surface methodology helps one arrive at the best condition of optimization of the parameters, and one term of the RSM should not be independently evaluated. For example, for the response SSA, the increase in temperature leads to an increase in the response; however, the term $\mathrm{A}^{2}$ (quadratic of temperature) leads to a decrease in SSA. The same trend was observed for the yielding mass response. The increase in temperature led to a decrease in the mass yielding; however, the term $\mathrm{A}^{2}$ leads to an increase. This observation is possible using statistical response surface methodology and could not be achieved using one-factor optimization (univariate optimization).

The effect of the variables of the BC preparation on SSA and mass yielding values is further studied through contour plots (shown in Figure 2). This plot makes it possible to observe the behavior of the variables' levels where a region with higher values can be found (represented by dark green areas). In addition, dashed arrows in red were inserted to show the maximum response on SSA and mass yielding to facilitate the visualization.
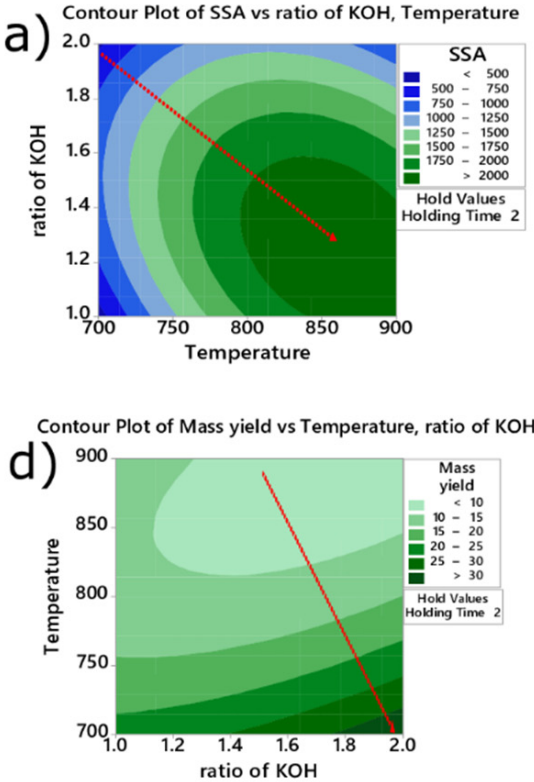
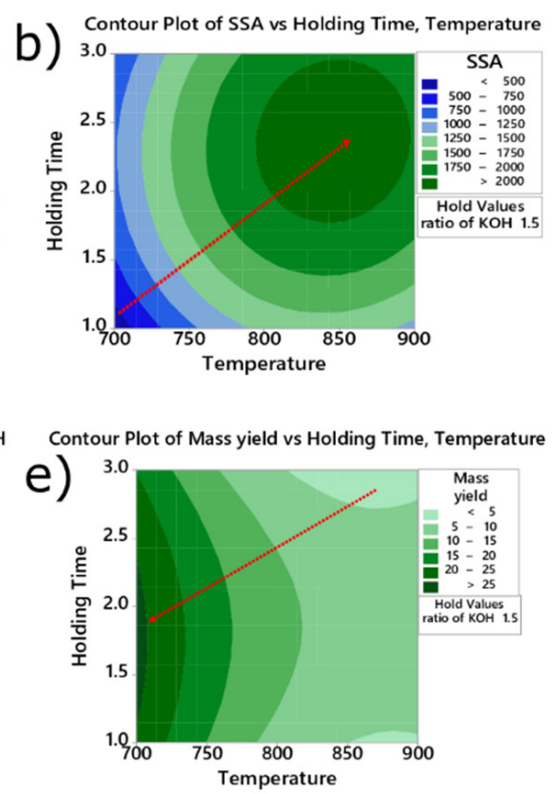
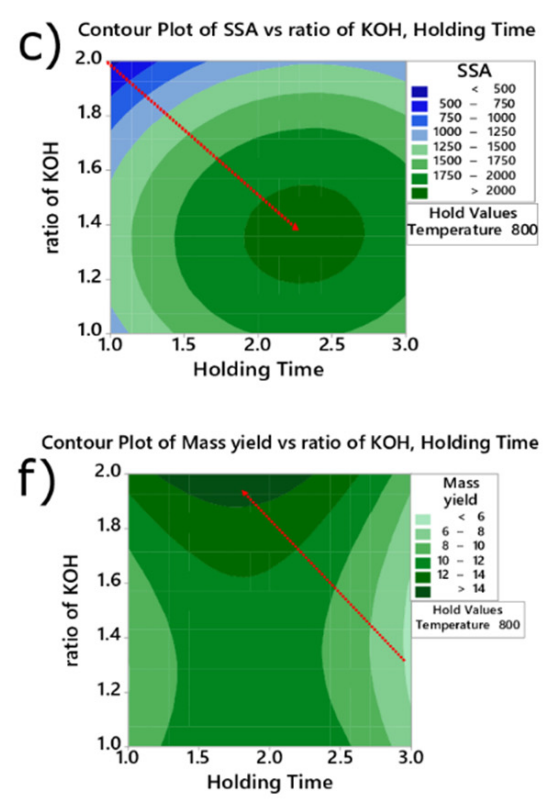

Figure 2. Contour plots of SSA and mass yielding versus each pair of parameters. Contour Plot of SSA vs. ratio of $\mathrm{KOH}$, Temperature (a); Contour Plot of SSA vs. Holding Time, Temperature (b); Contour Plot of SSA vs. ratio of $\mathrm{KOH}$, Holding (c); Contour Plot of Mass yield vs. Temperature, ratio of $\mathrm{KOH}(\mathbf{d})$; Contour Plot of Mass yield vs. Holding Time, Temperature (e); Contour Plot of Mass yield vs. ratio of $\mathrm{KOH}$, Holding Time (f).

According to Figure 2a-c (SSA as a response), the highest SSA values can be obtained at high temperatures but with a low ratio of $\mathrm{KOH}$. Regarding SSA for holding time versus temperature, the holding time should be between $2 \mathrm{~h} 30 \mathrm{~min}$ and $2 \mathrm{~h} 45 \mathrm{~min}$, the response for ratio versus time, and the ratio between 1.25-1.50. When the response was the ratio of biomass: activating agent, (Figure $2 \mathrm{~d}-\mathrm{f}$ ), the maximum mass yielding took place when the temperature was lower $\left(700^{\circ} \mathrm{C}\right.$ - see Figure $\left.2 \mathrm{~d}, \mathrm{f}\right)$ using a ratio of biomass: activating agent of 1:2 (see Figure 2e) and holding time of 1.5-2.0 h (Figure 2e).

The surface area is a factor that is crucial for obtaining adsorbents with high sorption capacity. Adsorbents that present high surface areas usually present high sorption capacities to remove different species [3,4]. From the economic point of view, the yield is an important parameter that can be a decisive issue in the industrial scale-up process. Therefore, an optimization should involve the two responses, surface area, and mass yielding. Figure 3 presents a graph that is the optimization of both responses. 


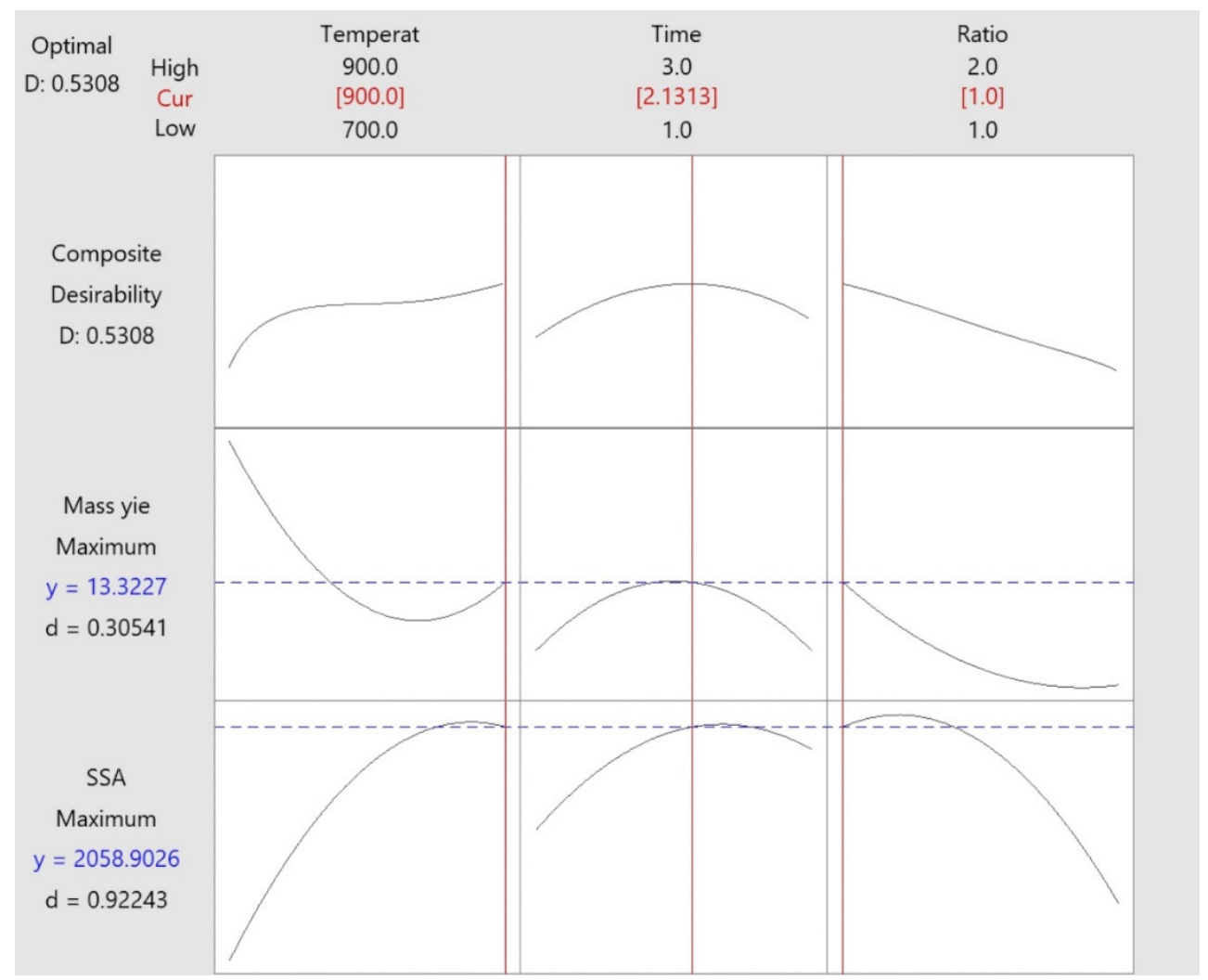

Figure 3. Optimization of the response mass yielding and SSA for production of BC.

The overall desirability for optimization of the maximum SSA and mass yielding of produced $\mathrm{BC}$ responses was 0.5308 . According to this optimization, it would be recommended to use a holding temperature of $900{ }^{\circ} \mathrm{C}$, a holding time of $2.13 \mathrm{~h}$, and a ratio of biomass: $\mathrm{KOH}$ of 1:1.

\section{2. $B$ Cs Characterization}

\subsubsection{Textural Properties and Morphology of BCs}

Specific surface area and porosity are essential properties that play a strong influence on the performances of the $\mathrm{BC}$ regarding its application, e.g., as an adsorbent for removing pollutants from residual water $[1,5,14]$. Therefore, four samples (BC6, BC4, BC11, and $\mathrm{BC} 7)$ were chosen to evaluate these properties. The choice was based on the highest and lowest SSA values and intermediate values.

Nitrogen adsorption-desorption isotherms of the four samples are presented in Figure 4. According to the IUPAC classification [26], isotherms of BC6 and BC4 are close to type I as the nitrogen adsorption increases at low partial pressure. This type describes an adsorption process resulting in micropores filling. As a consequence, BC6 and BC4 should contain certain quantities of micropores. However, both curves did not reach a limiting value, and the shape of isotherms at high partial pressure is closer to type IV isotherms. This type is typical of a mesoporous material. Moreover, a small $\mathrm{H} 4$ hysteresis loop is seen on BC6's isotherm, which indicates that the structure is mesoporous and microporous [26]. 

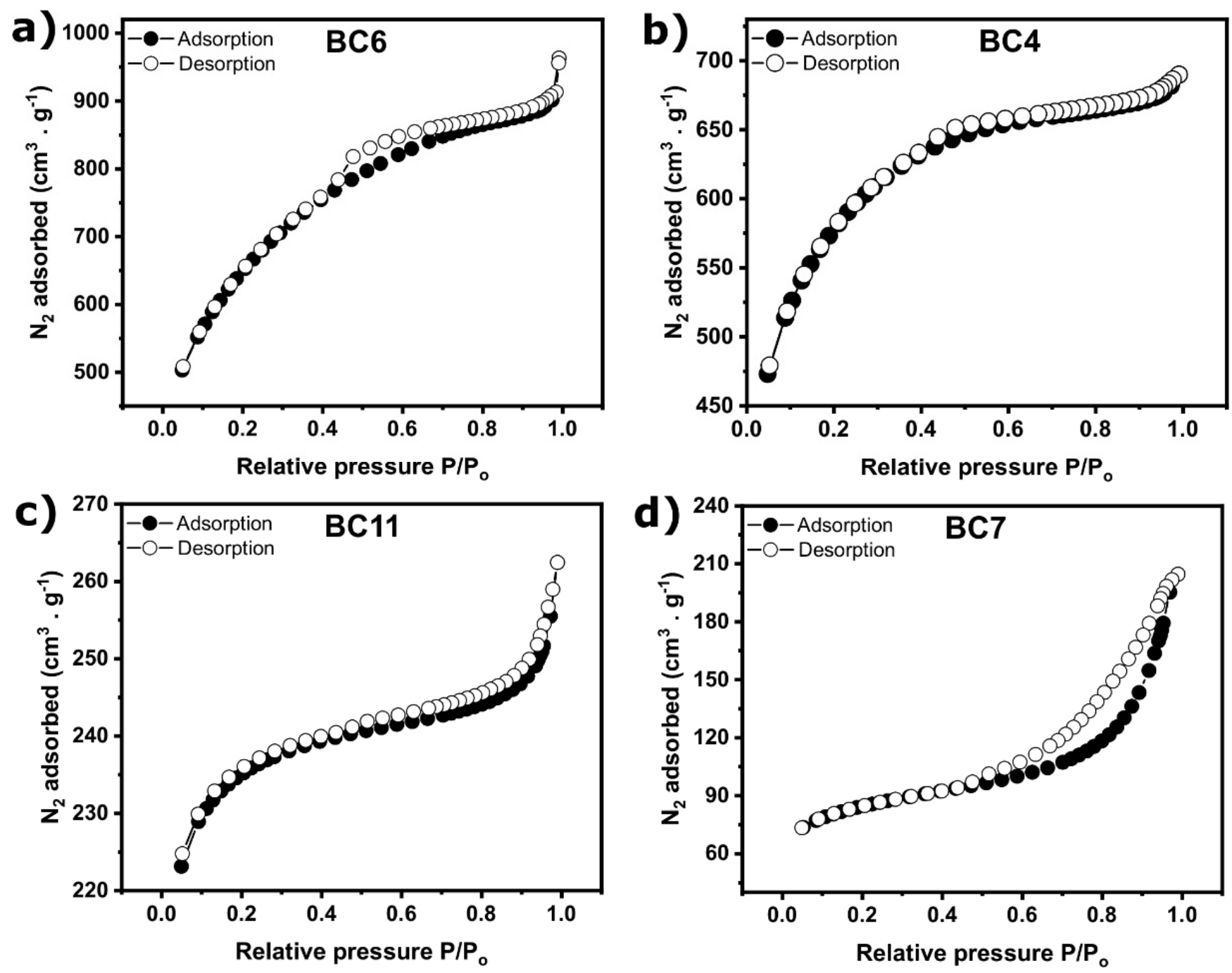

Figure 4. Nitrogen adsorption-desorption isotherms of (a) BC6, (b) BC4, (c) BC11, and (d) BC7.

On the other hand, BC11 and BC7 show a type IV isotherm (characteristic of mesoporous materials). In addition, the hysteresis is very distinct on BC7's curve, which indicates that mesopores are wider than $4 \mathrm{~nm}$, while it is not distinct at all for BC11's isotherm because mesopores are small. Moreover, according to Figure 4c,d, BC11 and BC7 also adsorb $\mathrm{N}_{2}$ at low partial pressure, which means they should present a combination of micropores and micropores in their structure.

The porosity of these four samples has been further studied by plotting the pore size distribution curves (see Figure 5). The four samples contain a rich structure of micropores with a pore diameter of $1.72 \mathrm{~nm}$. The highest micropores are observed for sample BC6, despite small mesopores with a diameter between 2 and $10 \mathrm{~nm}$. The volume of micropores is higher for BC6 and BC4, which have a higher specific surface area than BC11 and BC7. BC7's pore size distribution curve indicates the presence of wide mesopores with a diameter between $17.6 \mathrm{~nm}$ and $40.7 \mathrm{~nm}$. These results are in agreement with the results observed in the nitrogen adsorption isotherms. 

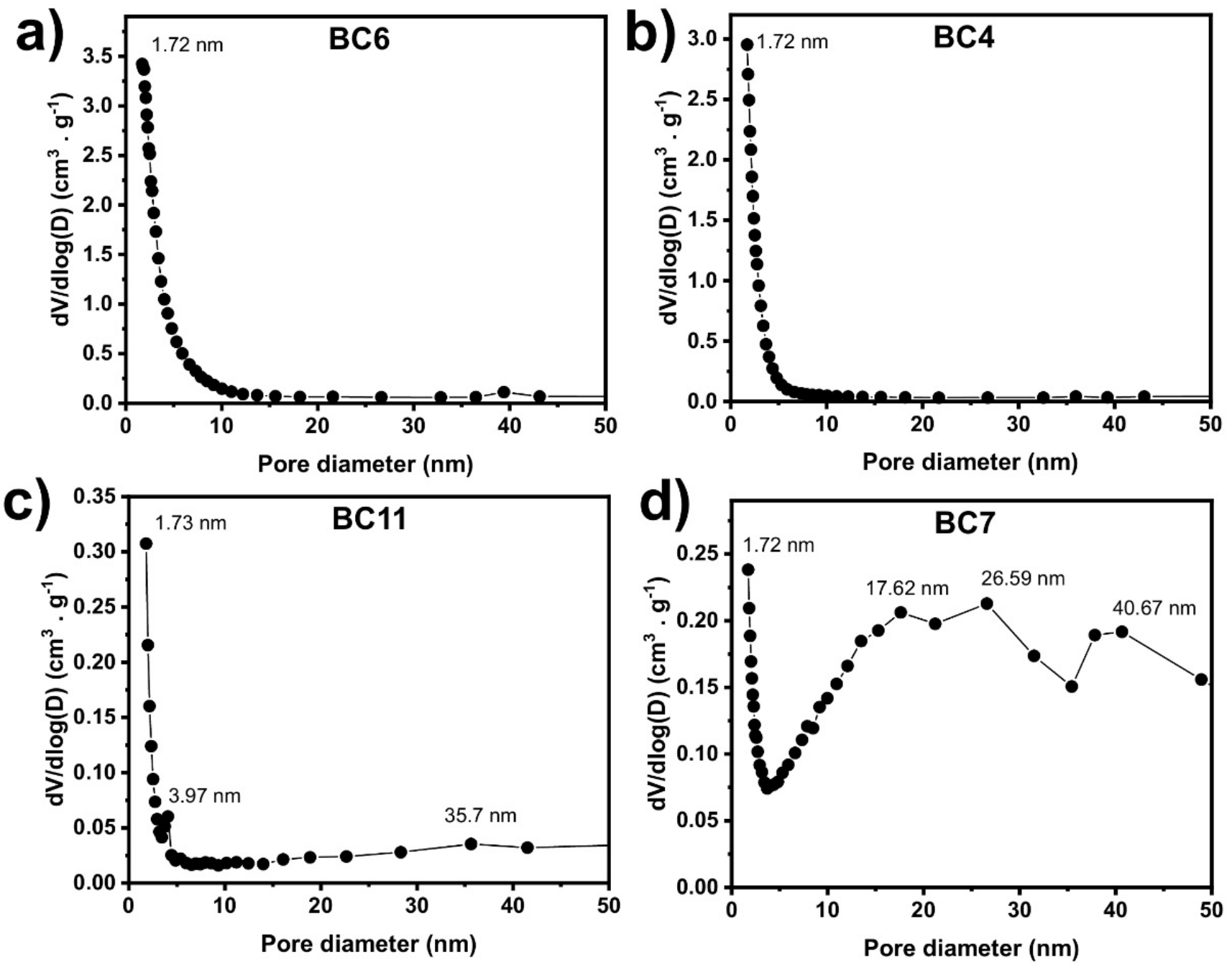

Figure 5. Pore size distribution of (a) BC6, (b) BC4, (c) BC11, and (d) BC7.

Results on microporosity and mesoporosity contributions in the BC are summarized in Table 3. As can be seen in Table 3, a high amount of microporous is observed in all samples. As indicated by $S_{\text {micro }}$ and $S_{\text {micro\% }}$ values, the spruce bark BCs showed to be composed of more micropores; for instance, the percentages of micropores (with relation to SSA values) of BC6, BC4, BC11, and BC7 were $77.4 \%, 56.3 \%, 86.4 \%$, and 54.7\%, respectively. However, large quantities of mesopores are also observed, especially for the samples BC7 (43.7\%) and BC6 (45.3\%). Micropores and mesopores are highly desirable in BCs for adsorption because they ensure wetting and liquid transport throughout the bulk of the BC.

Table 3. Microporosity and mesoporosity data of the four selected samples.

\begin{tabular}{ccccc}
\hline Sample's Name & $\mathbf{S}_{\text {meso }}\left(\mathbf{m}^{\mathbf{2}} \cdot \mathbf{g}^{-\mathbf{1}}\right)$ & $\mathbf{S}_{\text {micro }}\left(\mathbf{m}^{2} \cdot \mathbf{g}^{-\mathbf{1}}\right)$ & $\mathbf{S}_{\mathbf{m e s} \mathbf{\%}}(\mathbf{\%})$ & $\mathbf{S}_{\text {micro\% }} \mathbf{( \% )}$ \\
\hline BC6 & 499 & 1710 & 22.6 & 77.4 \\
BC4 & 825 & 1061 & 43.7 & 56.3 \\
BC11 & 99 & 627 & 13.6 & 86.4 \\
BC7 & 124 & 150 & 45.3 & 54.7 \\
\hline
\end{tabular}

To examine the effect of pyrolysis conditions and $\mathrm{KOH}$ activation on the surface morphology of the BCs, they were subjected to SEM analysis. Figure 6 shows the surface morphology of the four BCs. The SEM images display that all samples present spongestructures with roughness and irregular structure with big holes and cavities, which seem 
to be more significant for the BC6 and BC4 (see Figure 6a,b), following the SSA and pore structure results. Thus, by the SEM analysis, it is possible to infer that the preparation condition did influence the surface characteristics of the BCs. In addition, the images also show a significant presence of macropores and ultra-macropores, especially in BC11 and BC7. Macropores are also important because if the BCs are used as adsorbents to remove pollutants from waters, they serve as vectors of the solution passage through macropores until it attains smaller pores (in the interior of the BCs).

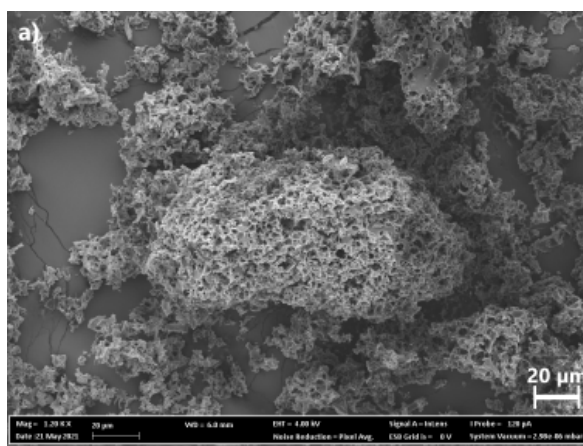

b)
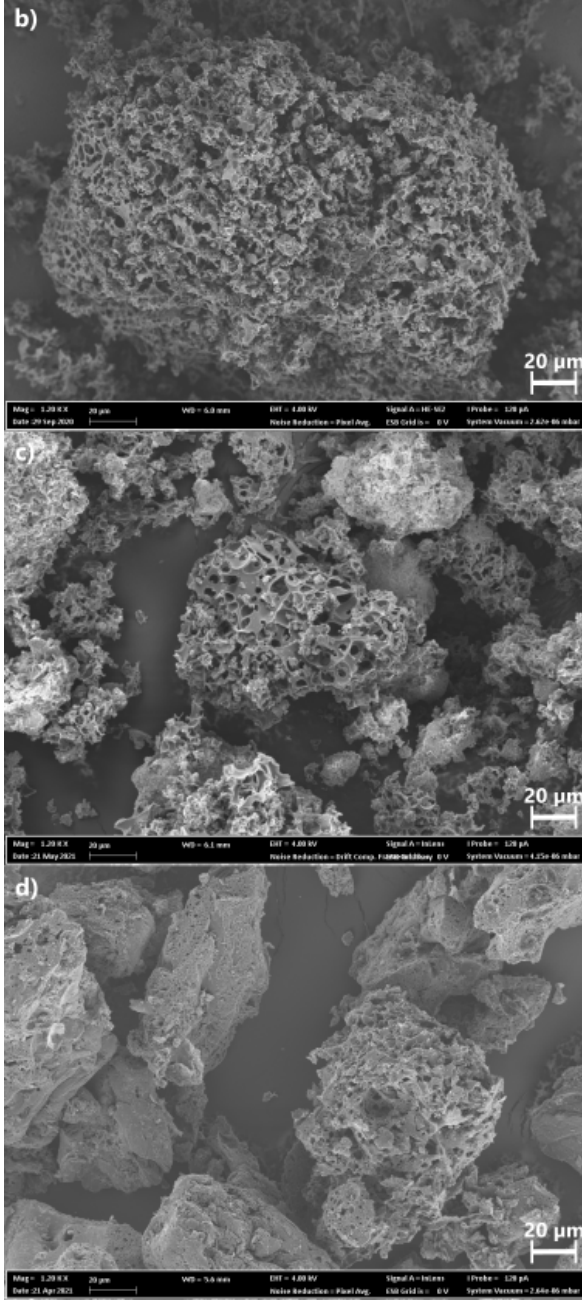
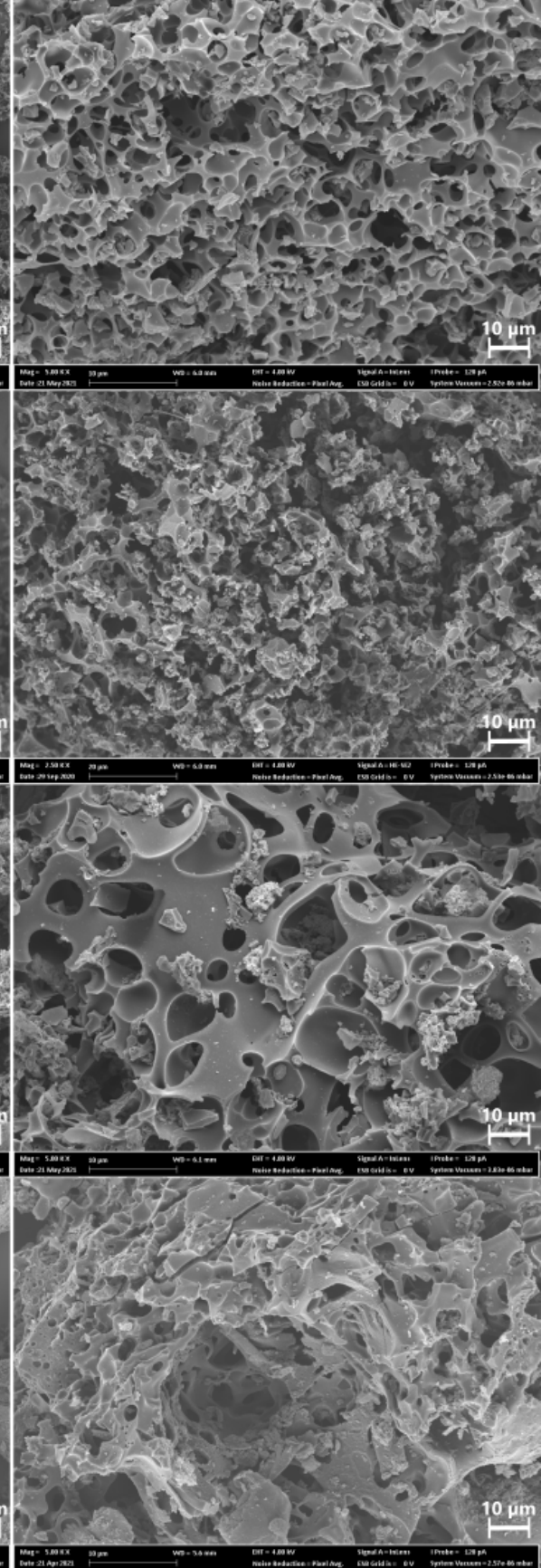

Figure 6. SEM images at a $20 \mu \mathrm{m}$ scale (on the left) and a $10 \mu \mathrm{m}$ scale (on the right) of (a) BC6, (b) BC4, (c) BC11, and (d) BC7.

\subsubsection{Chemical Characterization}

XPS analysis gives valuable information on different surface compositions of BC, which may be caused by the different pyrolysis conditions and oxidative alkaline treatment. 
Figure 7 shows $\mathrm{C} 1 \mathrm{~s}, \mathrm{O} 1 \mathrm{~s}$, and $\mathrm{N}$ 1s spectra, corresponding to carbon, oxygen, and nitrogen bonds, respectively.
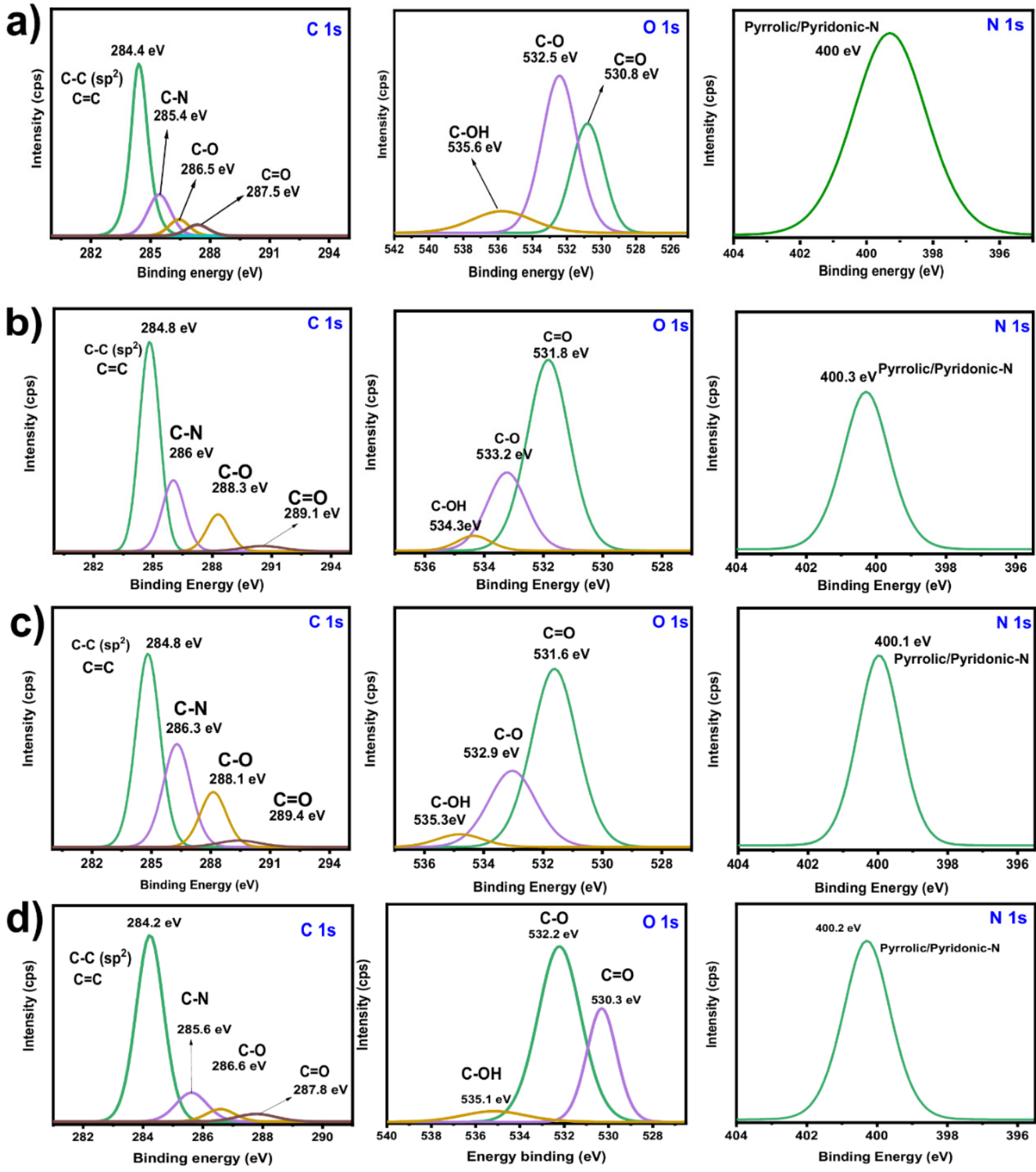

Figure 7. XPS spectra for (a) BC6, (b) BC4, (c) BC11, and (d) BC7.

The asymmetric $C 1$ s spectra can be deconvoluted into four peaks which are assigned to $\mathrm{C}-\mathrm{C}$ and $\mathrm{C}=\mathrm{C}$ (aromatic and aliphatic groups), $\mathrm{C}-\mathrm{N}, \mathrm{C}-\mathrm{O},(\mathrm{C}-\mathrm{O}-\mathrm{C})$, and $(\mathrm{C}=\mathrm{O})$ bonds, as seen in Figure 7. O 1s spectra were deconvoluted in three oxygen-chemical states, which might correspond to oxygen double-bonded with carbon in carbonyl structures $(\mathrm{C}=\mathrm{O})[27,28]$, esters $(\mathrm{O}=\mathrm{C}-\mathrm{OC})$, and carboxyl $(\mathrm{O}=\mathrm{C}-\mathrm{OH})$ groups $[29]$, as presented in Figure 7. The spectrum for the $\mathrm{N} 1 \mathrm{~s}$ exhibits a single peak at around $400 \mathrm{eV}$ that is attributed to pyrrolic/pyridinic nitrogen (graphitic-N species) [30].

The main composition of the BC taken from XPS analysis is shown in Table S2. All selected BCs contain more than $86 \%$ of carbon and more than $8.5 \%$ of oxygen. The high 
oxygen content indicates the abundance of functionalities on BCs surfaces. More precisely, the selected BC samples contain between 2 and $3 \%$ of carbonyl groups $(C=O)$. The amount of hydroxyl $(\mathrm{C}-\mathrm{OH})$ and ether $(\mathrm{C}-\mathrm{O}-\mathrm{C})$ groups are between 5 and $6 \%$. According to the XPS results, the chemical activation with potassium hydroxide is more effective in increasing the number of functional groups on BCs surfaces. It is well known that the surface functional groups are responsible for improving the adsorption process through electrostatic interactions and chemisorption-based processes $[2,3]$.

FTIR was used to examine the presence of the functional groups on the biochar samples (see Figure S1). The results show that the sample BC6, which presented the highest SSA and was prepared with the highest temperature $\left(900^{\circ} \mathrm{C}\right)$, displayed lesser functional groups and peaks with lower intensities (see Figure S1a). This suggests that at high temperatures functional groups can be lost due to the high volatilization of the compounds in the carbonaceous materials. On the other hand, the sample BC7 seems to have more peaks and with higher intensities (see Figure S1d). BC7 was prepared at $700^{\circ} \mathrm{C}$.

As can be seen, all samples presented similar spectrums, and the main difference is in the intensity of the bands (see Figure S1); the band at $3462-3473 \mathrm{~cm}^{-1}$ are assigned to stretching of $\mathrm{O}-\mathrm{H}$ groups with intermolecular $\mathrm{H}$ bonding $[5,9,14]$, and the small peaks at around 2926-2970 $\mathrm{cm}^{-1}$ are related to the asymmetric and symmetric $\mathrm{CH}$ - stretching $[5,9,14]$.

The small peaks around $1635-1639 \mathrm{~cm}^{-1}$ are related to the stretch of the carbonyl group $(\mathrm{C}=\mathrm{O})$ of carboxylic acids. The small bands at around 1429 and $1444 \mathrm{~cm}^{-1}$ can be attributed to ring modes of aromatics in the biochar chains $[5,9,14]$. The bands between 1255 and $1285 \mathrm{~cm}^{-1}$ can be attributed to the $\mathrm{C}-\mathrm{O}$ stretch of phenols or ethers $[5,9,14]$. The band at around 1028 and $1034 \mathrm{~cm}^{-1}$ are attributed to $\mathrm{CO}-$ of alcohols. The small vibrational bands between 791 and $887 \mathrm{~cm}^{-1}$ might be assigned to out of plane $\mathrm{C}-\mathrm{H}$ bends $[5,9,14]$.

Raman spectroscopy was performed to evaluate further the structure and degree of graphitization of the BCs. The obtained spectrum and intensity ratio of the four BCs are shown in Figure 8. Two distinct Raman shifts are observed in the spectra. The first one (D-peak), between 1300 and $1450 \mathrm{~cm}^{-1}$, is a characteristic scattering peak of graphitic structures. The second one (G-peak), between 1550 and $1650 \mathrm{~cm}^{-1}$, is a consequence of lattice defects, disordered arrangement, and the low symmetry carbon structure of graphite [31], characteristic of aromatic rings and hetero rings, especially aromatic amines [32,33]. These two functional groups are the main components of the BCs. The presence of nitrogen in samples is highlighted by XPS analysis.

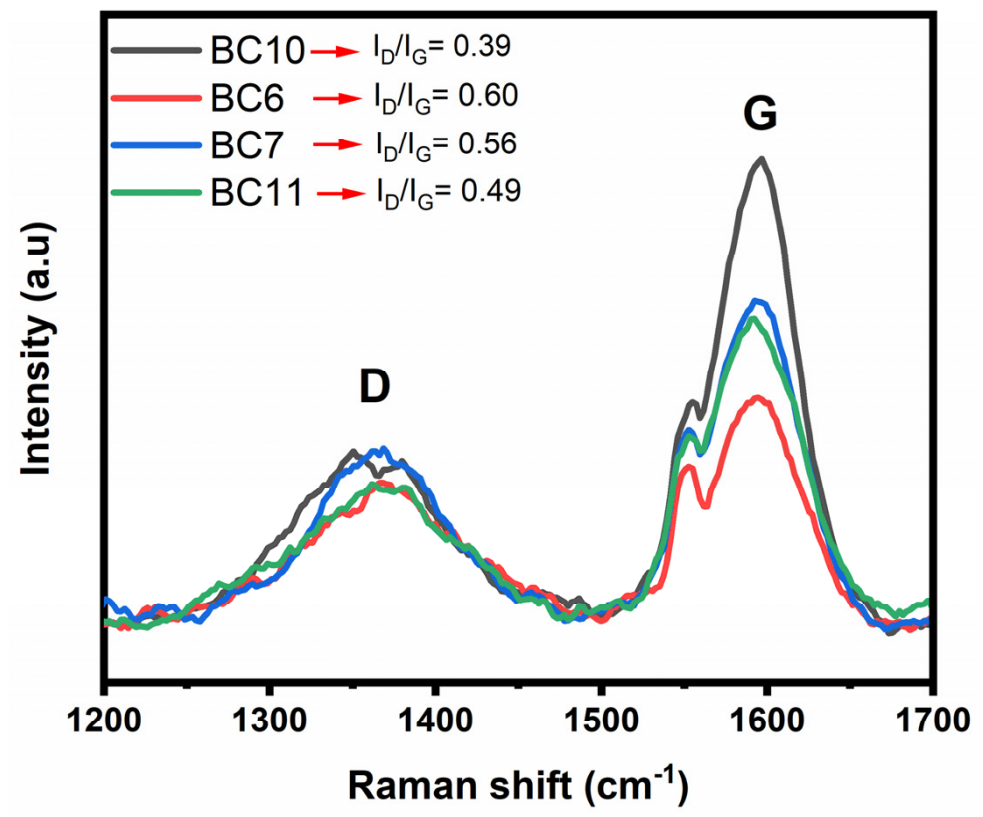

Figure 8. Raman spectra of the BCs. 
The degree of graphitization can be evaluated using the ratio of intensities of the D-peaks and G-peaks $\left(\mathrm{I}_{\mathrm{D}} / \mathrm{I}_{\mathrm{G}}\right)$ [34]. A smaller $\mathrm{I}_{\mathrm{D}} / \mathrm{I}_{\mathrm{G}}$ value suggests a higher degree of graphitization. In this sense, the four $\mathrm{I}_{\mathrm{D}} / \mathrm{I}_{\mathrm{G}}$ ratios are shown in the inset, confirming the resulting material's graphite structure. The lowest $\mathrm{I}_{\mathrm{D}} / \mathrm{I}_{\mathrm{G}}$ value reveals the more ordered graphitic structures [34], revealing that BC6 is the more ordered one. It is also the one with the highest SSA. However, it does not seem that the SSA is precisely correlated with the degree of ordination.

Hydrophobic behavior has been studied, and the ratios between n-heptane and water adsorbed by the 15 samples are shown in Figure 9. All samples, except 2, have a ratio below 1, which means that they are more hydrophilic than hydrophobic. These results may prove that the chemical activation by $\mathrm{KOH}$ has a significant effect on the surface functional groups of the BCs. Indeed, as carbonaceous materials, it is expected that material is more hydrophobic than hydrophilic. However, the XPS indicated the presence of hydrogen and oxygen groups, which are known to increase the hydrophilicity of the BC samples $[4,35]$. Thus, hydrophilicity and hydrophobicity could perfectly influence the performance of the $\mathrm{BC}$ during the adsorption process through hydrophilic and hydrophobic interactions $[9,35]$.

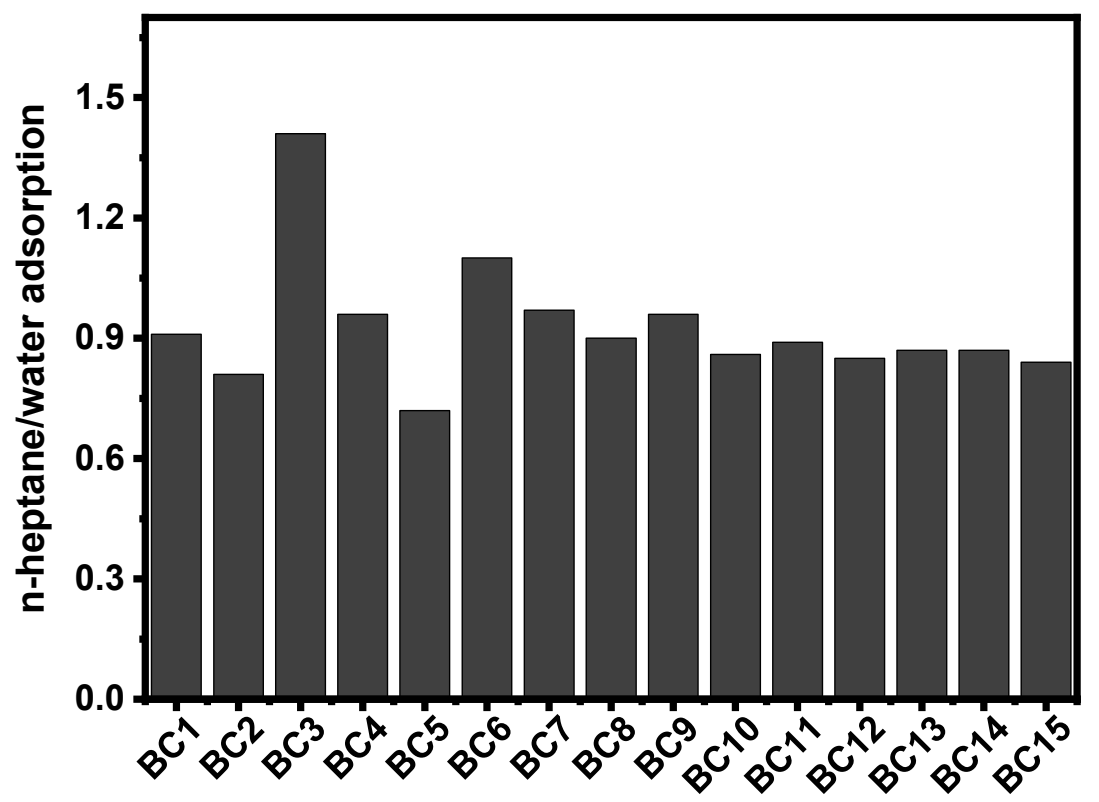

Figure 9. Hydrophobicity/hydrophilicity index of the biochars based on ratio of n-heptane/water adsorption.

\subsection{Evans Blue Removal}

The adsorption experiments were performed with the BC6 made at $900{ }^{\circ} \mathrm{C}, 2 \mathrm{~h}$, and biomass: $\mathrm{KOH}$ ratio of $1: 1$ — the sample with the highest SSA value $\left(2209 \mathrm{~m}^{2} \cdot \mathrm{g}^{-1}\right)$. Since the adsorption efficiency is highly dependent on the porous carbon textural properties, the highest SSA value justifies the choice of BC10 to be selected to be applied as an active matrix for adsorption.

\subsubsection{Effect of $\mathrm{pH}$ and Point of Zero Charge}

The $\mathrm{pH}$ of a solution is one of the most crucial parameters that affect the adsorption process [36-43]. The $\mathrm{pH}$ effect in the EB removal was performed in the range of 2-10 at initial concentration of $150 \mathrm{mg} \mathrm{L}^{-1}$. The results are shown in Figure 10. It seems that the $\mathrm{pH}$ played an important role during adsorption of anionic EB dye. Lower percentage removal was shown at basic $\mathrm{pH}$, while at acid $\mathrm{pH}$, the $\mathrm{EB}$ removal increased. The lower removal efficiency at higher $\mathrm{pH}$ might be because of competitive adsorption between $\mathrm{OH}-$ and the anionic EB dye with the biochar surface $[36,37,41]$. This suggests that the EB 
removal also takes place due to the electrostatic interactions, since it is dependent of the $\mathrm{pH}$ values $[36,37,41,42]$.

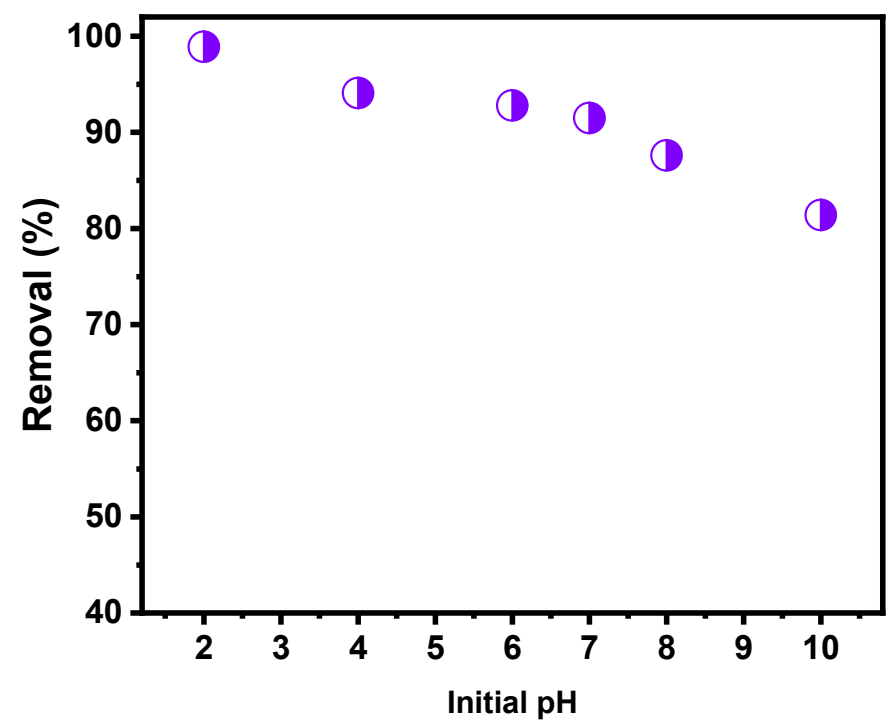

Figure 10. $\mathrm{pH}$ effect on the $\mathrm{EB}$ dye removal onto BC6. Adsorption experimental conditions: the initial adsorbate concentration was $150 \mathrm{~m} \mathrm{~L}^{-1}$; the contact time was $4 \mathrm{~h}$; the temperature was $23^{\circ} \mathrm{C}$; adsorbent dosage of $1.5 \mathrm{~g} \mathrm{~L}^{-1}$.

Similar results were found by Prola et al. [36] in their study, which employed multiwalled carbon nanotubes and activated carbon to adsorb EB dye. They found that the removal of EB dye decreased with the increase in the $\mathrm{pH}$ initial solution. Based on the $\mathrm{pH}$ studies, the next adsorption experiments were carried out with $\mathrm{pH}$ EB dye solutions at around 7.0 ( $\mathrm{pH}$ of the prepared EB working solutions), being unnecessary to make any $\mathrm{pH}$ adjustments.

To further evaluate the effect of the $\mathrm{pH}$ on the EB removal, the point of zero charge of BC6 was determined. The $\mathrm{p}_{\mathrm{HPZC}}$ value obtained for the BC6 was 6.83 (see Figure S2). For $\mathrm{pH}$ values lower than $\mathrm{pH}_{\mathrm{pzc}}$, the biochar presents a positive surface charge $[12,14,36]$. The dissolved EB dye is negatively charged in an aqueous solution because it possesses four sulphonate groups $[12,14,36]$. Then, the EB adsorption is maximized when the biochar has a positive surface charge. Electrostatic interactions occur between biochar and $\mathrm{EB}$ at a $\mathrm{pH}$ higher than 6.83. However, when the $\mathrm{pH}$ value is much lower than $\mathrm{pH}_{\mathrm{pzc}}$, the surface of the biochar becomes more positive. This phenomenon explains the high adsorption capacity at pH 2.0.

\subsubsection{Kinetic Study}

The elucidation of the dominant mechanism involved in the adsorption process, such as diffusion control and mass transport processes, is conveniently addressed by kinetics assays. The kinetics of adsorption of EB on selected BC is explored using nonlinear pseudo first-order (PFO), pseudo second-order (PSO), and general-order (GO) kinetic models.

The kinetic curves and fitting parameters of the models are shown in Figure 11a and Table 4 . The suitability of the models was evaluated through the determination coefficient $\mathrm{R}^{2}$ adj and standard deviation (SD) [42-49]. The general-order model is the most suitable model because it presents the highest $\mathrm{R}^{2}$ adj and lowest SD values (Table 4). The generalorder model suggests that the adsorption order should follow the same trend as that of a chemical reaction $[36,44]$. Considering the general-order kinetic equation, the order of reaction $(n)$ is found to be 33.87, suggesting that EB adsorption processes onto BC6 are complex and need to be further studied. 

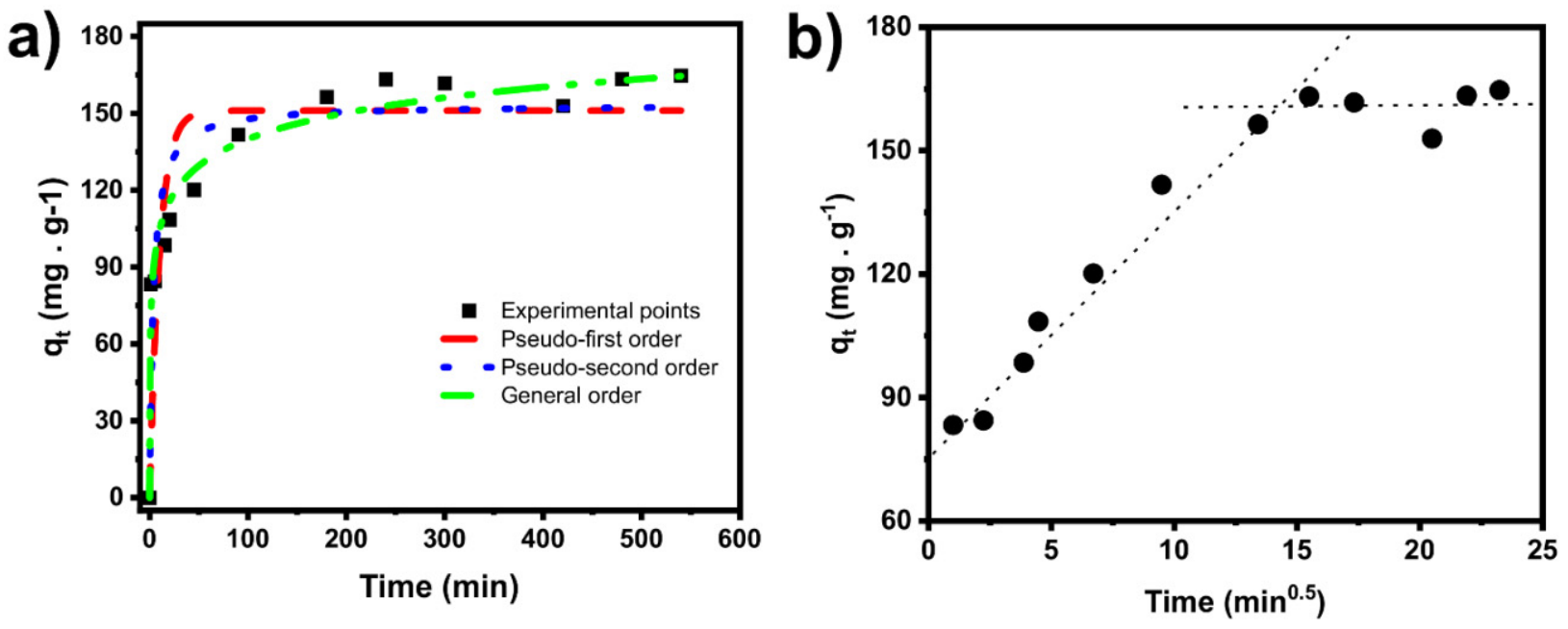

Figure 11. Kinetic fitting models and BC6 experimental curve (a) and intraparticle diffusion modeling (b).

Table 4. Kinetic fitting parameters.

\begin{tabular}{|c|c|}
\hline \multicolumn{2}{|c|}{ Kinetic Models } \\
\hline Pseudo first-order model & \\
\hline $\mathrm{q}_{1}\left(\mathrm{mg} \mathrm{g}^{-1}\right)$ & 148.7 \\
\hline $\mathrm{k}_{1}\left(\min ^{-1}\right)$ & 0.09438 \\
\hline$R^{2}$ & 0.5832 \\
\hline $\mathrm{R}^{2}$ adj & 0.5534 \\
\hline $\mathrm{SD}\left(\mathrm{mg} \mathrm{g}^{-1}\right)$ & 31.73 \\
\hline \multicolumn{2}{|l|}{ Pseudo second-order model } \\
\hline $\mathrm{q}_{2}\left(\mathrm{mg} \mathrm{g}^{-1}\right)$ & 158.7 \\
\hline $\mathrm{k}_{2}\left(\mathrm{~g} \mathrm{mg}^{-1} \min ^{-1}\right)$ & $9.602 \times 10^{-4}$ \\
\hline $\mathrm{R}^{2}$ & 0.7209 \\
\hline $\mathrm{R}_{\text {adj }}^{2}$ & 0.7010 \\
\hline $\mathrm{SD}\left(\mathrm{mg} \mathrm{g}^{-1}\right)$ & 25.96 \\
\hline \multicolumn{2}{|l|}{ General-order model } \\
\hline $\mathrm{q}_{\mathrm{n}}\left(\mathrm{mg} \cdot \mathrm{g}^{-1}\right)$ & 630.0 \\
\hline $\mathrm{kn}\left(\left(\mathrm{g} \cdot \mathrm{mg}^{-1}\right)^{\mathrm{n}-1} \cdot \mathrm{min}^{-1}\right)$ & $4.420 \times 10^{-28}$ \\
\hline $\mathrm{n}(-)$ & 33.87 \\
\hline $\mathrm{R}^{2}$ & 0.9681 \\
\hline $\mathrm{R}^{2}$ adj & 0.9617 \\
\hline $\mathrm{t}_{0.5}$ & 1.5 \\
\hline $\mathrm{t}_{0.95}$ & 139.4 \\
\hline $\mathrm{SD}\left(\mathrm{mg} \mathrm{g}^{-1}\right)$ & 432.0 \\
\hline
\end{tabular}

Since BC6 is highly porous, physical adsorption may play an essential role in the EB adsorption process. To demonstrate, intraparticle diffusion is exhibited in Figure 11b. The adsorption dynamics include two stages. The first stage, the longest one, can be related to boundary diffusion, where the EB is diffused on the BC exterior surface and to the bigger pores $[23,36]$. In the second stage, the EB is adsorbed and diffused from the bigger to the interior of smaller pores, followed by the equilibrium $[23,36]$.

Further evaluating the kinetic process, $\mathrm{t}_{0.5}$ and $\mathrm{t}_{0.95}$ were studied. The values were calculated from the best model (general-order model). These values correspond to the times (min) when $50 \%$ and $95 \%$ of saturation $\left(\mathrm{q}_{\mathrm{e}}\right)$ are attained, respectively [22-24].

Due to BC6's textural properties and chemical surface features, fast adsorption kinetics are observed from the values of $\mathrm{t}_{0.5}$ and $\mathrm{t}_{0.95}$. BC6 presented a high SSA and high amount of micropores and mesopores (see Table 2), which can explain the fast and good EB adsorption performance. 
The adsorption procedure was further continued by establishing the contact times of $150 \mathrm{~min}(2.5 \mathrm{~h})$. The established contact time was slightly higher than the $\mathrm{t}_{0.95}$ to ensure that the adsorption process had enough time to reach the equilibrium between EB and BC6, because $t_{0.95}$ will attain $95 \%$ saturation; the equilibrium should be established in the condition of complete saturation of the adsorbent.

\subsubsection{Isotherm Study}

The equilibrium of the adsorption process is one of the most critical pieces of information for the correct understanding of an adsorption process. In addition, it gives reliable information about the adsorption mechanism pathways and effective design of the adsorption system [37].

The equilibrium system between $\mathrm{EB}$ and the BC was evaluated using the nonlinear fitting of the Langmuir, Freundlich, and Redlich-Peterson models, and the obtained data are displayed in Figure 12 and Table 5.

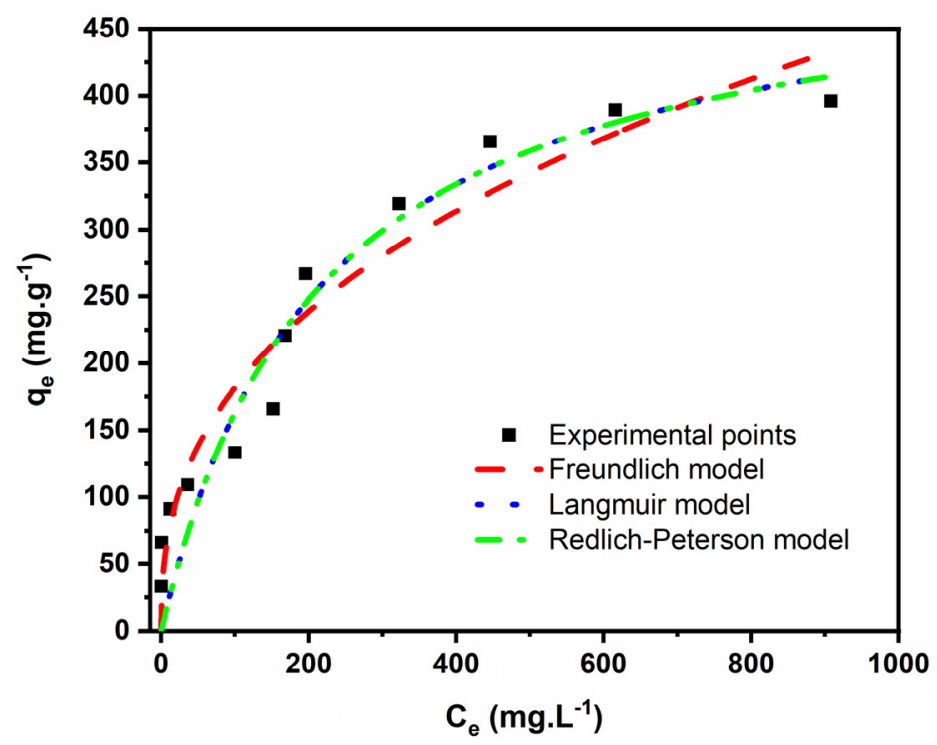

Figure 12. Adsorption isotherms of BC6 and the fitted models.

Table 5. Isotherm fitting parameters.

\begin{tabular}{|c|c|}
\hline \multicolumn{2}{|c|}{ Isotherm Models } \\
\hline Langmuir & \\
\hline $\mathrm{Q}_{\max }\left(\mathrm{mg} \mathrm{g}^{-1}\right)$ & 511.5 \\
\hline $\mathrm{K}_{\mathrm{L}}\left(\mathrm{L} \mathrm{mg}^{-1}\right)$ & 0.004700 \\
\hline $\mathrm{R}^{2}$ & 0.9198 \\
\hline $\mathrm{R}_{\text {adj }}^{2}$ & 0.9117 \\
\hline $\mathrm{SD}\left(\mathrm{mg} \mathrm{g}^{-1}\right)^{2}$ & 39.08 \\
\hline Freundlich & \\
\hline $\mathrm{K}_{\mathrm{F}}\left(\left(\mathrm{mg} \mathrm{g}^{-1}\right)\left(\mathrm{mg} \mathrm{L}^{-1}\right)^{-1 / n F}\right)$ & 29.66 \\
\hline $\mathrm{n}_{\mathrm{F}}$ & 2.540 \\
\hline $\mathrm{R}^{2}$ & 0.9318 \\
\hline$R_{\text {adj }}^{2}$ & 0.9250 \\
\hline $\mathrm{SD}\left(\mathrm{mg} \mathrm{g}^{-1}\right)^{2}$ & 36.02 \\
\hline Redlich-Peterson & \\
\hline $\mathrm{K}_{\mathrm{RP}}\left(\left(\mathrm{mg} \cdot \mathrm{g}^{-1}\right) \cdot\left(\mathrm{mg} \cdot \mathrm{L}^{-1}\right)^{-1}\right)$ & 2.403 \\
\hline $\mathrm{a}\left(\left(\mathrm{mg} \cdot \mathrm{L}^{-1}\right)^{-\mathrm{b}}\right)$ & 0.004700 \\
\hline $\mathrm{B}$ & 1.000 \\
\hline $\mathrm{R}^{2}$ & 0.9198 \\
\hline $\mathrm{R}^{2}$ adj & 0.9019 \\
\hline $\mathrm{SD}\left(\mathrm{mg} \mathrm{g}^{-1}\right)$ & 41.19 \\
\hline
\end{tabular}


Based on that $\mathrm{R}^{2}$ Adj and $\mathrm{SD}$ values, the Freundlich isotherm model was the most suitable model for all three BCs because it presented the highest $\mathrm{R}^{2}$ Adj and lowest SD values. Freundlich's model indicates that the adsorption process occurs on heterogeneous surfaces and active sites with different energies (which is the case of our BC) based on multilayer adsorption. For this model, an $\mathrm{n}$ value between 0 and 10 suggests favorable adsorption. The $n$ value found in this work was 2.54 .

The Freundlich model does not give maximum adsorption value $\left(\mathrm{Q}_{\max }\right)$, but the experimental adsorption capacity for the EB onto BC6 was very high $\left(396.1 \mathrm{mg} \cdot \mathrm{g}^{-1}\right)$. The physicochemical properties of BC6 can explain the efficiency of EB removal. Besides its very high SSA $\left(2209 \mathrm{~m}^{2} \cdot \mathrm{g}^{-1}\right)$, it also presented a very high pore volume equal to $1.49 \mathrm{~cm}^{3} \cdot \mathrm{g}^{-1}$. It is well known that pore volume plays a decisive role in the overall adsorption, as SSA does [9]. Higher pore volume leads to higher sorption capacity [9]. The EB molecule has a maximum diagonal length of $2.04 \mathrm{~nm}$ [36], a size that can be accommodated inside some pores of $\mathrm{BC} 6$.

\subsubsection{EB Dye Mechanism of Adsorption on Biochar}

Based on the biochar's physicochemical characterization, such as SSA, pore size, FTIR, and XPS-as well as the adsorption results, such as the initial $\mathrm{pH}$ solution, kinetics of adsorption, and equilibrium studies-it was possible to suggest the primary mechanisms of adsorption for EB on biochar (see Figure 13).

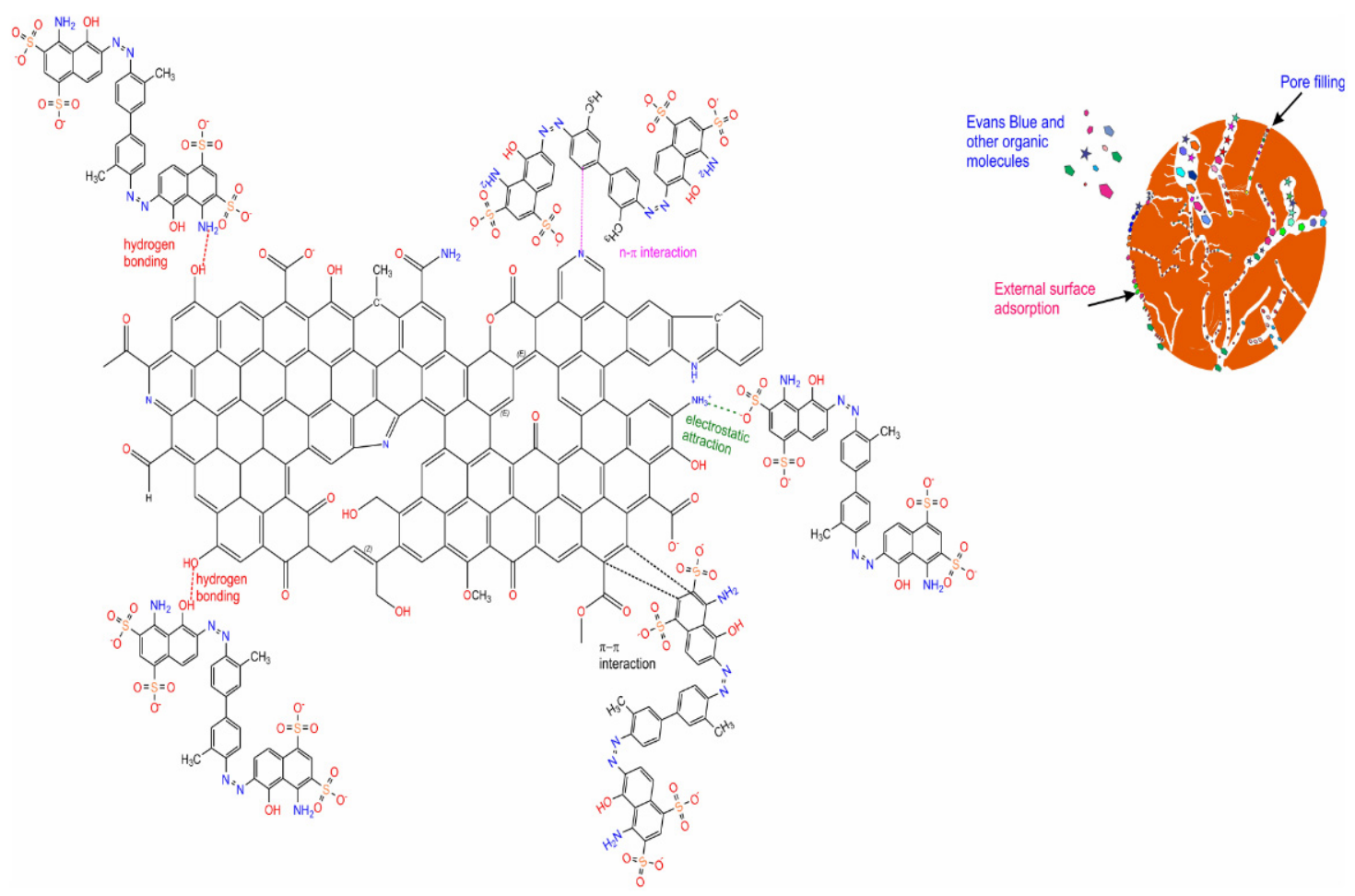

Figure 13. Proposed mechanism of adsorption.

The adsorption process takes place through different physical interactions between biochar surface and EB dye such as hydrogen bonding and $\pi-\pi$ and $n-\pi$ interactions of the aromatic ring of the biochar with the aromatic rings of the EB dye [36,43,48]. Hydrogen bonding is formed with the azo groups of the dye with the hydroxyl groups present on the biochar's surface $[36,43,48] . \pi-\pi$ and $n-\pi$ interactions (donor-acceptor interactions) occur among aromatic rings in the biochar structure that act as an electron acceptor (see Figure S2). Besides, the aromatic rings of the $\mathrm{EB}$ dye molecules interact with the $\mathrm{C}=\mathrm{O}, \mathrm{OH}, \mathrm{COOH}$, and phenyl groups of the biochar that act as adsorption sites (see Figure 13) $[36,43,48]$. 
However, since the biochar has highly developed porosity and elevated SSA, another mechanism that takes place is the pore-filling. The pore-filling can be the most prominent process that contributes to the high adsorption efficiency for EB dye onto highly porous biochar (see Figure 13).

\subsubsection{EB Adsorption Performance over Norway Spruce BC and Other Adsorbents:}

Comparison with the Literature

The adsorption tests strongly indicated that Norway spruce bark BC efficiently removed EB from aqueous solutions. Although the nature of every adsorbent is different and each absorbent has its own merits and demerits, here, we have provided comparison data in which the adsorbent dose, $\mathrm{pH}$, and maximum adsorption capacity are taken into consideration. The values were obtained at the best experimental conditions of each work. As a result, it can be seen that the adsorption efficiency of the EB molecules on Norway spruce BC was very high in comparison with other listed adsorbents in Table 6.

Table 6. Comparison of EB adsorption capacity on Norway spruce bark BC and other parameters obtained from the different materials reported in the literature.

\begin{tabular}{|c|c|c|c|c|c|c|}
\hline Biomass & $\begin{array}{l}\text { Dosage } \\
\left(\mathrm{g} \cdot \mathrm{L}^{-1}\right)\end{array}$ & $\mathrm{pH}$ & Isotherm Model & Kinetic Model & $\underset{\left(\mathrm{mg} \cdot \mathrm{g}^{-1}\right)}{\mathrm{Q}_{\max }}$ & Ref. \\
\hline $\begin{array}{c}\text { Magnetic spinel } \mathrm{ZnFe}_{2} \mathrm{O}_{4} \\
\text { nanomaterial }\end{array}$ & 0.2 & 7.0 & Freundlich & Pseudo Second Order & 45.45 & [19] \\
\hline Commercial activated carbon & 1.5 & 2.0 & Liu & General-order & 135.2 & [36] \\
\hline Multiwalled carbon nanotube & 1.5 & 2.0 & Liu & General-order & 409.4 & [36] \\
\hline Rarasaponin-bentonite & 10.0 & - & Toth & Pseudo First Order & 495.8 & [38] \\
\hline $\begin{array}{c}\text { Calcined } \mathrm{Cu}-\mathrm{Al}-\mathrm{CO}_{3} \text { layered } \\
\text { double hydroxide materials }\end{array}$ & 4.0 & 6.0 & Langmuir & 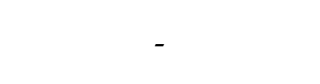 & 333.3 & [39] \\
\hline $\begin{array}{l}\text { Perovskite lanthanum } \\
\text { aluminate nanoparticles }\end{array}$ & 0.6 & 7.0 & Langmuir & $\begin{array}{l}\text { pseudo-second- } \\
\text { order }\end{array}$ & 40.82 & [40] \\
\hline $\mathrm{Mg}-\mathrm{Al}-\mathrm{CO}_{3}$ & 0.5 & 6.0 & langmuir & & 107.5 & [41] \\
\hline $\begin{array}{c}\text { Aqai palm stalk (Euterpe } \\
\text { oleracea) }\end{array}$ & 2.5 & 2.0 & Sips & $\begin{array}{l}\text { Avrami fractional } \\
\text { order }\end{array}$ & 45.1 & [43] \\
\hline Norway spruce bark BC & 1.5 & 7.0 & Redlich-Peterson & General-order & 396.1 * & This work \\
\hline
\end{tabular}

* Experimental q, Redlich-Peterson model does not provide $\mathrm{Q}_{\max }$.

It is worth discussing that, among the reported adsorbents, the synthesized BC exhibited the third-highest sorption capacity; however, the first one (multiwalled carbon nanotube) and the second one (rarasaponin-bentonite) are materials that present more complex preparation methodologies; therefore, higher costs are involved in comparison with a single step $\mathrm{KOH} \mathrm{BC}$ process. Consequently, the $\mathrm{BC}$ can be considered a cost-efficient adsorbent due to its facile fabrication process being an effective prototype from the environmental perspective for removing azo dyes and possibly other organic pollutants from wastewater.

\subsubsection{Synthetized Wastewater Treatment Tests}

As previously observed, sample BC6 was very efficient in removing EB from aqueous solutions. Consequently, it is expected that it could be effectively employed in the treatment of wastewaters composed of compounds commonly found in industrial wastewaters. Therefore, two synthetic wastewaters loaded with seven dyes and other organic and inorganic compounds (see Table S1) were employed to test the ability of the BC10 to clean them up (see Figure 14). 

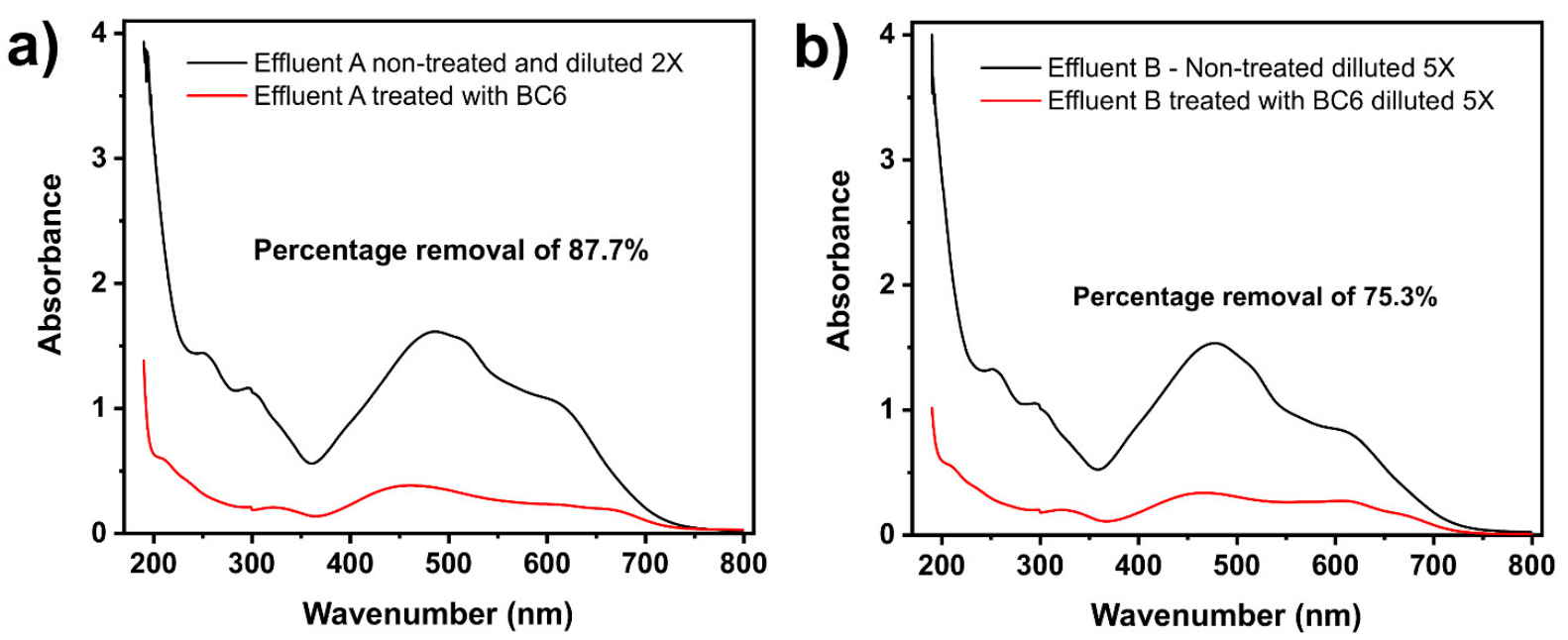

Figure 14. Spectra of effluents A (a) and B (b) treated and non-treated by BC10.

The calculation of the percentage removal was performed taking into account the UV-vis spectra area of the two synthetic effluents before and after the treatment under the band of absorption from 190 to $800 \mathrm{~nm}[43,44,48]$ (see Figure 13).

The spectra show very high removal percentages for both effluents: $87.7 \%$ for effluent A (low concentration) and $75.5 \%$ for effluent B (highly concentrated). These results strongly support the practical application of the $\mathrm{KOH}$-activated Norway spruce bark in treating real colorful wastewater.

\subsubsection{Regeneration Studies}

The reuse of the biochar after the adsorption process makes them even more important, given their low cost and their ability to regenerate. It is crucial for environmental and cost reasons for adsorbents to have good recyclability. Usually, this is carried out by leaching-out the adsorbed dye with alcohol or a basic solution with a $\mathrm{pH}$ at which dye adsorption is very low.

The BC6 sample was subjected to four adsorption-desorption cycles. The tests were performed at EB dye initial concentration of $200 \mathrm{mg} \mathrm{L}^{-1}$, an adsorbent dosage of $1.5 \mathrm{~g} \mathrm{~L}^{-1}$. Two eluents were put in contact with the biochar loaded with EB dye (solutions of $0.1 \mathrm{M}$ $\mathrm{NaOH}+20 \% \mathrm{EtOH}$ and $0.25 \mathrm{M} \mathrm{NaOH}+20 \% \mathrm{EtOH}$ ) (see Figure 15).

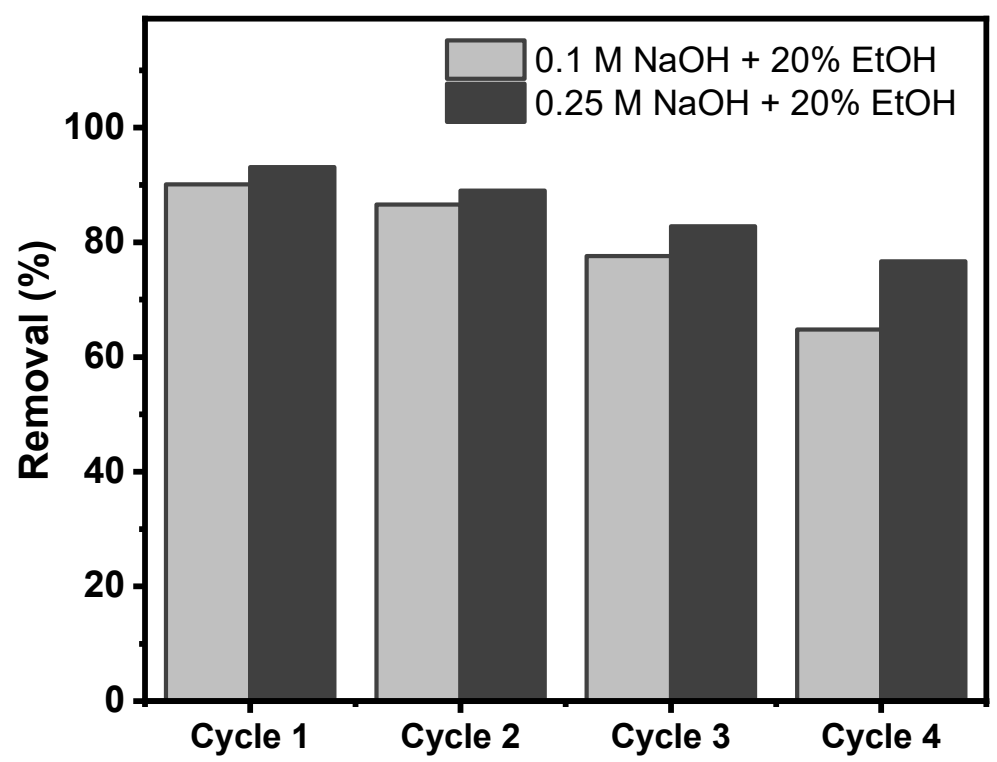

Figure 15. Effect of the eluent on the desorption and adsorption-desorption cycles. 
The results depicted in Figure 15 suggests impressive adsorption performance after five continuous adsorption-desorption cycles of the BC6, for both eluents. It was observed that the adsorption capacity of the BC6 kept at very high level, with a reduction of $4.1 \%$, $10.3 \%$, and $16.4 \%$ after second, third, and fourth cycles, respectively, for the eluent $0.25 \mathrm{M}$ $\mathrm{NaOH}+20 \% \mathrm{EtOH}$.

As the main takeaway of the regeneration results, the biochar exhibited very good reusability even after a fourth cycle. Thus, further experiments on testing different eluents could help the biochar to reach even higher adsorption performances after four cycles.

\section{Materials and Methods}

\subsection{Chemicals and Reagents}

The Holmen paper industry provided the Norway spruce bark. The spruce bark was dried and milled at medium particle size of $500 \mu \mathrm{m}$ with a Fritsch Pulverisette 14 miller. The chemicals potassium hydroxide $(\mathrm{KOH})$, Evans blue dye $\left(\mathrm{C}_{34} \mathrm{H}_{24} \mathrm{~N}_{6} \mathrm{Na}_{4} \mathrm{O}_{14} \mathrm{~S}_{4}\right)$, and hydroxide chloride $(\mathrm{HCl})$ were purchased from Sigma-Aldrich. The chemical structure of the Evans blue dye is shown in Figure S3.

\subsection{Preparation Process}

The BCs were prepared by following the method described as follows: First, $15.0 \mathrm{~g}$ of bark was mixed with $\mathrm{KOH}$ at different ratios (biomass: $\mathrm{KOH}, 1: 1,1: 1.5$, and 1:2, weight), and mixed with $30 \mathrm{~mL}$ of distilled water in a melting pot, until a homogeneous paste is obtained. The mixtures were left for $2 \mathrm{~h}$ at ambient temperature and then placed in a stove, at $105{ }^{\circ} \mathrm{C}$, for a day before being pyrolyzed following the RSM procedure. The pyrolysis occurred in a Carbolite Gero Elf $11 / 23$ chamber furnace under a $600 \mathrm{~cm}^{3} \mathrm{~min}^{-1}$ nitrogen flow at different pyrolysis conditions. After pyrolysis, the samples were milled and washed with $1.0 \mathrm{M}$ hydrochloric acid solution to remove the remaining chemical reagent. The washing step was performed using a proportion of $100 \mathrm{~mL}$ of $\mathrm{HCl}$ to $15 \mathrm{~g}$ of pyrolyzed sample. Both $\mathrm{BC}$ and $\mathrm{HCl}$ solution was placed in a flat-bottomed flask under a reflux system at $75{ }^{\circ} \mathrm{C}$ for $1 \mathrm{~h}$ and magnetically stirred at $300 \mathrm{rpm}[4,5]$. Afterward, the acid solution was separated from the solid samples by filtration. In order to complete the BC preparation, a washing step with distilled water was performed several times until the $\mathrm{pH}$ value of the filtrate reached a neutral value [4,5]. The wet BCs were finally drought in a $100{ }^{\circ} \mathrm{C}$ stove over the night for further uses.

\subsection{Response Surface Methodology (RSM)}

In order to obtain BCs with optimized properties, the influence of pyrolysis variables (pyrolysis temperature, holding time, and ratio of activating agent) was studied (see Table 1).

The RSM experiments were designed using a Box-Behnken design (BBD). A 3-variables, level Box-Behnken design, consisting of 15 experimental runs, was adopted to optimize the experimental data, including 3 replications at the center point, as shown in Table 1 . The plan was automatically generated using Minitab software, which was explored to verify the variables' influence on the responses (SSA and mass yield).

\section{BC Characterization}

The textural properties of BCs were evaluated through nitrogen adsorption-desorption isotherms by using a Tristar 3000 apparatus, Micrometrics Instrument Corp. The BC samples were subjected to degasification at $180^{\circ} \mathrm{C}$ for $3 \mathrm{~h}$ in a nitrogen atmosphere. The specific surface area (SSA) and pore size distribution were obtained using the BrunauerEmmett-Teller (BET) method [8].

The morphology of BCs was studied through scanning electron microscopy (SEM) using a Zeiss-Gemini microscope, and pictures are made at $10 \mu \mathrm{m}$ and $20 \mu \mathrm{m}$ scales.

XPS spectra were collected using a Kratos Axis Ultra DLD electron spectrometer using a monochromated $\mathrm{Al} \mathrm{K}$ s source operated at $150 \mathrm{~W}$. An analyzer of $160 \mathrm{eV}$ for acquiring 
survey spectra and $20 \mathrm{eV}$ for individual photoelectron lines were used. The samples were gently hand-pressed using a clean Ni spatula into the powder sample holder. Because carbon material is conductive, no charge neutralization system was used. The binding energy (BE) scale was calibrated following the ASTM E2108 and ISO 15472 standards. Processing of the spectra was accomplished with the Kratos software.

Fourier transform infrared spectroscopy (FTIR) was exploited to determine the functional groups of the biochars. The FTIR spectra were recorded over the wavenumber range of 4000-400 $\mathrm{cm}^{-1}$, utilizing a Bruker IFS 66v/S instrument (Bruker Optics, Ettlingen, Germany) with an acquisition of 64 scans $\mathrm{min}^{-1}$ and resolution of $4 \mathrm{~cm}^{-1}$.

Raman spectra were collected using a Bruker Bravo spectrometer (Bruker, Ettlingen, Germany) connected to a docking measuring station. Shortly, $0.5 \mathrm{~g}$ of BC samples was manually ground using an agate mortar and pestle, placed in $2.5 \mathrm{~mL}$ glass vials, and scanned in the 300-3200 $\mathrm{cm}^{-1}$ spectral range at $4 \mathrm{~cm}^{-1}$ resolution for 256 scans. Min-max normalization over the $1000-2000 \mathrm{~cm}^{-1}$ region and smoothing (9 points) was carried out using the built-in functions of the OPUS software (v7, Bruker Optik GmbH, Ettlingen, Germany). No baseline correction was needed.

The hydrophobicity index (HI) was obtained according to a method reported by [42]: $0.3 \mathrm{~g}$ of each BC was added in $10 \mathrm{~mL}$ beakers and placed into plugged 1.5 L E-flasks with saturated atmosphere solvent vapor, $80 \mathrm{~mL}$ of each solvent (n-heptane or water). After $24 \mathrm{~h}$, the beakers were weighed. The weight gained was employed to calculate the adsorbed vapor sorption.

The $\mathrm{pH}_{\mathrm{pzc}}$ values were obtained by the relation between the initial $\mathrm{pH}_{\mathrm{i}}$ and the variation of $\mathrm{pH}\left(\mathrm{pH}_{\mathrm{f}}-\mathrm{pH}_{\mathrm{i}}\right)[33,36]$.

\subsection{Evans Blue (EB) Removal Process}

\subsubsection{Batch Adsorption Tests}

The adsorption tests were performed according to the reported in [9,42-44]. The EB stock solution of $2000 \mathrm{mg} \cdot \mathrm{L}^{-1}$ was diluted in several solutions in 50.0 to $1500 \mathrm{mg} \cdot \mathrm{L}^{-1}$. First, $30 \mathrm{mg}$ of BC were weighted in $50 \mathrm{~mL}$ Falcon tubes and put in contact with $20 \mathrm{~mL}$ of EB solution $\left(1.5 \mathrm{~g} \cdot \mathrm{L}^{-1}\right)$. Then, the tubes were agitated in a shaker model TE-240 from 1 to 540 min. Afterward, to separate the BCs from the EB solutions, the tubes were subjected to centrifugation at $5000 \mathrm{rpm}$ for $10 \mathrm{~min}$. Next, the supernatants were collected and placed into smaller tubes of $15 \mathrm{~mL}$ and centrifuged again at $5000 \mathrm{rpm}$ for $20 \mathrm{~min}$. Afterward, the residual EB was identified from curves in the UV spectrophotometer Shimadzu 1800 at $607 \mathrm{~nm}$.

The quantification of the EB adsorbed was calculated through Equation (1) (percentage of removal) and Equation (2) (adsorption capacity), as follows:

$$
\begin{gathered}
\% \text { Removal }=100 \cdot \frac{\left(C_{i}-C_{f}\right)}{C_{0}} \\
q=\frac{\left(C_{i}-C_{f}\right)}{m_{B C}} \cdot V_{\text {pollutant }}
\end{gathered}
$$

$\mathrm{q}$ is the removal capacity of adsorbed EB by the BCs $\left(\mathrm{mg} \cdot \mathrm{g}^{-1}\right) . \mathrm{C}_{\mathrm{i}}$ is the EB initial solution concentration in contact with the BCs $\left(\mathrm{mg} \cdot \mathrm{L}^{-1}\right) . \mathrm{C}_{\mathrm{f}}$ is the EB final concentration after adsorption (in $\left.\mathrm{mg} \cdot \mathrm{L}^{-1}\right) \cdot \mathrm{m}_{\mathrm{BC}}$ is the mass of $\mathrm{BCs}(\mathrm{g}) . \mathrm{V}_{\text {pollutant }}$ is the aliquot of the $\mathrm{EB}$ solution (L) introduced in the flask.

\subsubsection{Kinetic and Isotherm Models of Adsorption}

Pseudo first-order (PFO)—see Equation (3) — pseudo second-order (PSO)—see Equation (4) - and general-order (GO) models—see Equation (5)—were used to fit the kinetic data [43-45]. The corresponding equations of these respective models are summarized as follows:

$$
\mathrm{q}_{\mathrm{t}}=\mathrm{q}_{\mathrm{e}} \cdot\left[1-\exp \left(-\mathrm{k}_{1} \cdot \mathrm{t}\right)\right]
$$




$$
\mathrm{q}_{\mathrm{t}}=\mathrm{q}_{\mathrm{e}}-\frac{\mathrm{q}_{\mathrm{t}}=\frac{\mathrm{k}_{2} \cdot \mathrm{q}_{\mathrm{e}}^{2} \cdot \mathrm{t}}{1+\mathrm{q}_{\mathrm{e}} \cdot \mathrm{k}_{2} \cdot \mathrm{t}}}{\left[\mathrm{k}_{\mathrm{N}} \cdot\left(\mathrm{q}_{\mathrm{e}}\right)^{\mathrm{n}-1} \cdot \mathrm{t} \cdot(\mathrm{n}-1)+1\right]^{1 /(\mathrm{n}-1)}}
$$

where $\mathrm{t}$ is the contact time $(\mathrm{min}) ; \mathrm{q}_{\mathrm{t}}, \mathrm{q}_{\mathrm{e}}$ are the amount of adsorbate adsorbed at time $\mathrm{t}$ and the equilibrium $\left(\mathrm{mg} \cdot \mathrm{g}^{-1}\right)$, respectively; $\mathrm{k}_{1}$ is the pseudo first-order rate constant $\left(\mathrm{min}^{-1}\right)$; $\mathrm{k}_{2}$ is the pseudo second-order rate constant $\left(\mathrm{g} \cdot \mathrm{mg}^{-1} \cdot \mathrm{min}^{-1}\right) ; \mathrm{k}_{\mathrm{N}}$ is the general-order rate constant $\left(\left(\mathrm{mg} \cdot \mathrm{g}^{-1}\right)^{\mathrm{n}-1} \cdot \mathrm{min}^{-1}\right) ; \mathrm{n}$ is the order of the general-order model (dimensionless).

Langmuir's (Equation (6)), Freundlich's (Equation (7)), and Redlich-Peterson's (Equation (8)) models were employed for evaluating the EB equilibrium process [44], as follows:

$$
\begin{gathered}
\mathrm{q}_{\mathrm{e}}=\frac{\mathrm{Q}_{\max } \cdot \mathrm{K}_{\mathrm{L}} \cdot \mathrm{C}_{\mathrm{e}}}{1+\mathrm{K}_{\mathrm{L}} \cdot \mathrm{C}_{\mathrm{e}}} \\
\mathrm{q}_{\mathrm{e}}=\mathrm{K}_{\mathrm{F}} \cdot \mathrm{C}_{\mathrm{e}}^{1 / \mathrm{nF}} \\
\mathrm{q}_{\mathrm{e}}=\frac{\mathrm{K}_{\mathrm{RP}} \cdot \mathrm{C}_{\mathrm{e}}}{1+\mathrm{a}_{\mathrm{RP}} \cdot \mathrm{C}_{\mathrm{e}}^{\beta}}, \text { being } 0 \leq \beta \leq 1
\end{gathered}
$$

where $\mathrm{q}_{\mathrm{e}}$ is the adsorbate amount adsorbed at equilibrium $\left(\mathrm{mg}^{-1} \mathrm{~g}^{-1}\right) ; \mathrm{C}_{\mathrm{e}}$ is the adsorbate concentration at equilibrium $\left(\mathrm{mg} \cdot \mathrm{L}^{-1}\right) ; \mathrm{Q}_{\max }$ is the maximum sorption capacity of the adsorbent $\left(\mathrm{mg} \cdot \mathrm{g}^{-1}\right) ; \mathrm{K}_{\mathrm{L}}$ is the Langmuir equilibrium constant $\left(\mathrm{L} \cdot \mathrm{mg}^{-1}\right) ; \mathrm{K}_{\mathrm{F}}$ is the Freundlich

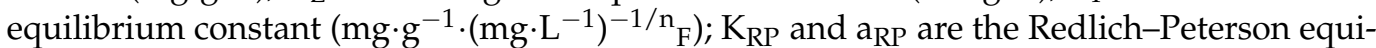
librium constant $\left(\left(\mathrm{mg} \cdot \mathrm{g}^{-1}\right) \cdot\left(\mathrm{mg} \cdot \mathrm{L}^{-1}\right)^{-1}\right.$ and $\left.\left(\mathrm{mg} \cdot \mathrm{L}^{-1}\right)^{-\beta}\right) ; \mathrm{n}_{\mathrm{F}}$ and $\beta$ are the exponents of Freundlich and Redlich-Peterson models, respectively (dimensionless).

The fitting of the kinetics and equilibrium data were evaluated by using nonlinear methods, which were provided by the Simplex method and the Levenberg-Marquardt algorithm using the fitting facilities of the Microcal Origin 2020 software [45-47]. The suitableness of the kinetic and equilibrium models was evaluated using the determination coefficient $\left(R^{2}\right)$, the adjusted determination coefficient $\left(R^{2}{ }_{\text {adj }}\right)$, and the standard deviation of residues (SD) [45-47], as shown in Equations (9)-(11), respectively:

$$
\begin{gathered}
R^{2}=\left(\frac{\sum_{i}^{n}\left(q_{i, \exp }-\bar{q}_{i, e x p}\right)^{2}-\sum_{i}^{n}\left(q_{i, e x p}-q_{i, \text { model }}\right)^{2}}{\sum_{i}^{n}\left(q_{i, \exp }-\bar{q}_{i, \exp }\right)^{2}}\right) \\
R_{a d j}^{2}=1-\left(1-R^{2}\right) \cdot\left(\frac{n-1}{n-p-1}\right) \\
S D=\sqrt{\left(\frac{1}{n-p}\right) \cdot \sum_{i}^{n}\left(q_{i, e x p}-q_{i, \text { model }}\right)^{2}}
\end{gathered}
$$

In the above equations, $\mathrm{q}_{\mathrm{i} \text { model }}$ is the theoretical $\mathrm{q}$ value predicted by the model; $\mathrm{q}_{\mathrm{i}, \exp }$ is the experimental $\mathrm{q}$ value; $\overline{\mathrm{q}}_{\mathrm{i}, \exp }$ is the average of all measured experimental $\mathrm{q}$ values; $\mathrm{n}$ is the number of experiments; $\mathrm{p}$ is the number of parameters in the fitting model. Values of $\mathrm{R}_{\text {adj }}^{2}$ and SD are used to compare different models of kinetics and equilibrium presented in this work. The best fitting model would present the highest $R^{2}$ adj and lowest $S D$ values [45,48-50]. Lower SD and higher $R^{2}$ adj values show a reduced disparity between experimental and theoretical q values and, therefore, a higher suitability of the model $[45,48,49]$.

\subsubsection{Application to Synthetized Effluents}

Two effluents were made, mixing seven dyes and different organic and inorganic compounds to simulate dye-composed effluents. The different compositions of these synthesized effluents are reported in Table S1. In order to prove the ability of the activated 
carbon for treating real effluents, a calculation of the percentage removal is performed, considering the UV-vis spectra area of the two effluents before and after the treatment under the band of the spectra [43].

\section{Conclusions}

Norway spruce bark BC, through $\mathrm{KOH}$ activation, yielded highly porous BC structures. The application of a BBD successfully optimized the production of BC with SSA up to $2209 \mathrm{~m}^{2} \cdot \mathrm{g}^{-1}$. Pyrolysis temperature was the only influential parameter over both responses (SSA and mass yield) within the parameters studied. The temperature influenced the SSA values positively, while the mass yield influenced negatively. In other words, the higher the SSA, the lower the yield.

The preparation process conditions influence the physicochemical properties of BC. The characterization results indicated that the BCs exhibited disordered carbon structures and presented a high quantity of $\mathrm{O}$-containing functional groups on their surfaces, which improved adsorption performance towards dyes removals.

The adsorption of Evans blue dye was tested with the BC with the highest SSA, and the kinetic study suggested that the general-order model best fitted the process. Furthermore, the intraparticle process indicated two stages in the EB adsorption process.

The equilibrium study suggested that the EB removal was better described by the Redlich-Peterson model, indicating that the process combines a monolayer and an infinite multilayer adsorption process. The highest adsorption capacity reached is $396.1 \mathrm{mg} \cdot \mathrm{g}^{-1}$. The employment of the BC in the treatment of synthetic effluents, with several dyes and other organic and inorganic compounds, returned a high percentage of removal degree up to $87.7 \%$.

Desorption and cyclability tests showed that the biochar can be efficiently regenerated maintaining an adsorption capacity of $75 \%$ after four adsorption-desorption cycles.

The very high SSA, high surface functionalities, chemical structure, and highly efficient EB adsorption capacity and effluents removal of the BCs show great potential for using Norway spruce bark as a precursor for the BC preparation with good results adsorption properties.

Supplementary Materials: The following supporting information can be downloaded. Table S1: Effluents' composition, Table S2: XPS elemental composition of the biochar samples (atom \%), Figure S1: FTIR absorption spectra of (a) BC6, (b) BC4, (c) BC11 and (d) BC7 samples, Figure S2: Point of zero charge curve of the BC6 sample, Figure S3: A- Structural formula of Evans blue dye; BOptimized three-dimensional structural formula of DB-53. The dimensions of the chemical molecule was calculated using ChemBio 3D Ultra version 12.0.

Author Contributions: Conceptualization, M.G., M.M. and G.S.d.R.; data curation, G.S.d.R., E.C.L. and G.L.D.; funding acquisition, S.H.L. and F.R.; investigation, M.G., M.M. and G.S.d.R.; methodology, M.G., M.M., E.C.L. and G.S.d.R.; project administration, S.H.L., M.G.M. and F.R.; software, M.G., M.M., I.P.A. and G.S.d.R.; writing-original draft, M.G., M.M. and G.S.d.R.; writing-review and editing, all authors. All authors have read and agreed to the published version of the manuscript.

Funding: This research received no external funding.

Institutional Review Board Statement: Not applicable.

Informed Consent Statement: Not applicable.

Data Availability Statement: Not applicable.

Acknowledgments: This research was funded by the Treesearch Postdoctoral program, Bio4Energya Strategic Research Environment appointed by the Swedish government, and the Swedish University of Agricultural Sciences. Guy and Mathieu thank ERASMUS for the financial support.

Conflicts of Interest: The authors declare no conflict of interest.

Sample Availability: Samples of the compounds are available from the authors. 


\section{References}

1. Enaime, G.; Baçaoui, A.; Yaacoubi, A.; Lübken, M. Biochar for Wastewater Treatment-Conversion Technologies and Appli-cations. Appl. Sci. 2020, 10, 3492. [CrossRef]

2. Li, S.; Chan, C.Y.; Sharbatmaleki, M.; Trejo, H.; Delagah, S. Engineered Biochar Production and Its Potential Benefits in a Closed-Loop Water-Reuse Agriculture System. Water 2020, 12, 2847. [CrossRef]

3. dos Reis, G.S.; Larsson, S.H.; de Oliveira, H.P.; Thyrel, M.; Claudio Lima, E. Sustainable Biomass Activated Carbons as Elec-trodes for Battery and Supercapacitors-A Mini-Review. Nanomaterials 2020, 10, 1398. [CrossRef]

4. dos Reis, G.S.; Larsson, S.H.; Mathieu, M.; Thyrel, M.; Pham, T.N. Application of design of experiments (DoE) for optimised production of micro- and mesoporous Norway spruce bark activated carbons. Biomass Convers. Biorefinery 2021, 1-19. [CrossRef]

5. dos Reis, G.; de Oliveira, H.; Larsson, S.; Thyrel, M.; Lima, E.C. A Short Review on the Electrochemical Performance of Hierarchical and Nitrogen-Doped Activated Biocarbon-Based Electrodes for Supercapacitors. Nanomaterials 2021, 11, 424. [CrossRef]

6. Zheng, C.; Yang, Z.; Si, M.; Zhu, F.; Yang, W.; Zhao, F.; Shi, Y. Application of biochars in the remediation of chromium con-tamination: Fabrication, mechanisms, and interfering species. J. Hazard. Mater. 2021, 407, 124376. [CrossRef] [PubMed]

7. Yaashikaa, P.R.; Kumar, P.S.; Varjani, S.; Saravanan, A. A critical review of biochar production techniques, characterization, stability, and applications for circular bio-economy. Biotechnol. Rep. 2020, 28, e00570. [CrossRef] [PubMed]

8. Molina-Sabio, M.; Rodríguez-Reinoso, F. Role of chemical activation in the development of carbon porosity. Colloids Surfaces $A$ Physicochem. Eng. Asp. 2004, 241, 15-25. [CrossRef]

9. Leite, A.B.; Saucier, C.; Lima, E.C.; Dos Reis, G.S.; Umpierres, C.S.; Mello, B.L.; Shirmardi, M.; Dias, S.; Sampaio, C.H. Activated carbons from avocado seed: Optimisation and application for removal of several emerging organic compounds. Environ. Sci. Pollut. Res. 2017, 25, 7647-7661. [CrossRef]

10. Dos Reis, G.S.; Wilhelm, M.; Silva, T.C.D.A.; Rezwan, K.; Sampaio, C.H.; Lima, E.C.; De Souza, S.M.G.U. The use of the design of experiments for the evaluation of the production of surface rich activated carbon from sewage sludge via micro-wave and conventional pyrolysis. Appl. Therm. Eng. 2016, 93, 590-597. [CrossRef]

11. Duan, X.; Peng, J.; Srinivasakannan, C.; Zhang, L.; Xia, H.; Yang, K.; Zhang, Z. Process Optimization for the Preparation of Activated Carbon from Jatropha Hull Using Response Surface Methodology. Energy Sources Part A Recover. Util. Environ. Eff. 2011, 33, 2005-2017. [CrossRef]

12. Moralı, U.; Demiral, H.; Şensöz, S. Optimization of activated carbon production from sunflower seed extracted meal: Taguchi design of experiment approach and analysis of variance. J. Clean. Prod. 2018, 189, 602-611. [CrossRef]

13. Abioye, A.M.; Abdulkadir, L.N.; Sintali, I.S.; Bawa, M.A.; Ani, F.N. Temperature Controlled Microwave-Induced CO 2 Ac-tivated Carbon: Optimization Using Box-Behnken Design. Adv. Eng. Res. 2020, 198, 129-135.

14. Viotti, P.V.; Moreira, W.M.; dos Santos, O.A.A.; Bergamasco, R.; Vieira, A.M.S.; Vieira, M. Diclofenac removal from water by adsorption on Moringa oleifera pods and activated carbon: Mechanism, kinetic and equilibrium study. J. Clean. Prod. 2019, 219, 809-817. [CrossRef]

15. Salari, M.; Rakhshandehroo, G.R.; Nikoo, M.R. Degradation of ciprofloxacin antibiotic by Homogeneous Fenton oxidation: Hybrid AHP-PROMETHEE method, optimization, biodegradability improvement and identification of oxidized by-products Chemosphere 2018, 206, 157-167. [CrossRef]

16. Banerjee, P.; Sau, S.; Das, P.; Mukhopadhayay, A. Optimization and modelling of synthetic azo dye wastewater treatment using Graphene oxide nanoplatelets: Characterization toxicity evaluation and optimization using Artificial Neural Network. Ecotoxicol. Environ. Saf. 2015, 119, 47-57. [CrossRef]

17. Satuf, M.L.; Pierrestegui, M.J.; Rossini, L.; Brandi, R.J.; Alfano, O.M. Kinetic modeling of azo dyes photocatalytic degradation in aqueous $\mathrm{TiO}_{2}$ suspensions. Toxicity and biodegradability evaluation. Catal. Today 2011, 161, 121-126. [CrossRef]

18. Yao, L.; Xue, X.; Yu, P.; Ni, Y.; Chen, F. Evans Blue Dye: A Revisit of Its Applications in Biomedicine. Contrast Media Mol. Imaging 2018, 2018, 7628037. [CrossRef]

19. Vergis, B.R.; Kottam, N.; Krishna, R.H.; Nagabhushana, B. Removal of Evans Blue dye from aqueous solution using magnetic spinel ZnFe2O4 nanomaterial: Adsorption isotherms and kinetics. Nano-Struct. Nano-Objects 2019, 18, 100290. [CrossRef]

20. Jinendra, U.; Bilehal, D.; Nagabhushana, B.M.; Jithendra Kumara, K.S.; Kollur, S.P. Nano-catalytic behavior of highly effi-cient and regenerable mussel-inspired $\mathrm{Fe}_{3} \mathrm{O}_{4} @ \mathrm{CFR} @ \mathrm{GO}$ and $\mathrm{Fe}_{3} \mathrm{O}_{4} @ \mathrm{CFR} @ \mathrm{TiO}_{2}$ magnetic nanospheres in the reduction of Evans blue dye. Heliyon 2021, 7, e06070. [CrossRef]

21. Yagmur, E.; Gokce, Y.; Tekin, S.; Semerci, N.I.; Aktas, Z. Characteristics and comparison of activated carbons prepared from oleaster (Elaeagnus angustifolia L.) fruit using $\mathrm{KOH}$ and $\mathrm{ZnCl}_{2}$. Fuel 2020, 267, 117232. [CrossRef]

22. Guclu, C.; Alper, K.; Erdem, M.; Tekin, K.; Karagoz, S. Activated carbons from co-carbonization of waste truck tires and spent tea leaves. Sustain. Chem. Pharm. 2021, 21, 100410. [CrossRef]

23. Bag, O.; Tekin, K.; Karagoz, S. Microporous activated carbons from lignocellulosic biomass by KOH activation. Full. Nanotub. Carbon Nanostructures 2020, 28, 1030-1037. [CrossRef]

24. Serafin, J.; Ouzzine, M.; Junior, O.F.C.; Sreńscek-Nazzal, J. Preparation of low-cost activated carbons from amazonian nutshells for $\mathrm{CO}_{2}$ storage. Biomass Bioenergy 2021, 144, 105925. [CrossRef]

25. Efeovbokhan, V.E.; Alagbe, E.; Odika, B.; Babalola, R.; Oladimeji, T.E.; Abatan, O.G.; Yusuf, E.O. Preparation and character-ization of activated carbon from plantain peel and coconut shell using biological activators. J. Phys. Conf. Ser. 2019, 1378, 032035 [CrossRef] 
26. Thommes, M.; Kaneko, K.; Neimark, A.V.; Olivier, J.P.; Rodriguez-Reinoso, F.; Rouquerol, J.; Sing, K.S.W. Physisorption of gases, with special reference to the evaluation of surface area and pore size distribution (IUPAC Technical Report). Pure Appl. Chem. 2015, 87, 1051-1069. [CrossRef]

27. Luo, Q.-P.; Huang, L.; Gao, X.; Cheng, Y.; Yao, B.; Hu, Z.; Wan, J.; Xiao, X.; Zhou, J. Activated carbon derived from melaleuca barks for outstanding high-rate supercapacitors. Nanotechnology 2015, 26, 304004. [CrossRef] [PubMed]

28. Ahmed, W.; Mehmood, S.; Qaswar, M.; Ali, S.; Khan, Z.H.; Ying, H.; Chen, D.Y.; Núñez-Delgado, A. Oxidized biochar ob-tained from rice straw as adsorbent to remove uranium (VI) from aqueous solutions. J. Environ. Chem. Eng. 2021, 9, 105104. [CrossRef]

29. Chen, R.; Li, L.; Liu, Z.; Lu, M.; Wang, C.; Li, H.; Ma, W.; Wang, S. Preparation and characterization of activated carbons from tobacco stem by chemical activation. J. Air Waste Manag. Assoc. 2017, 67, 713-724. [CrossRef]

30. Hu, Y.; Tong, X.; Zhuo, H.; Zhong, L.; Peng, X.; Wang, S.; Sun, R. 3D hierarchical porous N-doped carbon aerogel from renewable cellulose: An attractive carbon for high-performance supercapacitor electrodes and $\mathrm{CO}_{2}$ adsorption. RSC Adv. 2016, 6, 15788-15795. [CrossRef]

31. Reyhani, A.; Golikand, A.N.; Mortazavi, S.Z.; Irannejad, L.; Moshfegh, A.Z. The effects of multi-walled carbon nanotubes graphitization treated with different atmospheres and electrolyte temperatures on electrochemical hydrogen storage. Electrochim. Acta 2010, 55, 4700-4705. [CrossRef]

32. Larkin, P. Infrared and Raman Spectroscopy: Principles and Spectral Interpretation; Elsevier: Amsterdam, The Netherlands, 2011.

33. Smith, E.; Dent, G. Modern Raman Spectroscopy—A Practical Approach; Wiley: Chichester, UK, 2004.

34. Ranguin, R.; Ncibi, M.C.; Cesaire, T.; Lavoie, S.; Jean-Marius, C.; Grutzmacher, H.; Gaspard, S. Development and character-isation of nanostructured hybrid material with vitamin B12 and bagasse-derived activated carbon for anaerobic chlordecone (Kepone) removal. Environ. Sci. Pollut. Res. Int. 2020, 27, 41122-41131. [CrossRef] [PubMed]

35. Dos Reis, G.S.; Lima, E.C.; Sampaio, C.H.; Rodembusch, F.S.; Petter, C.O.; Cazacliu, B.G.; Dotto, G.L.; Hidalgo, G.E.N. Novel kaolin/polysiloxane based organic-inorganic hybrid materials: Sol-gel synthesis, characterization, and photocatalytic proper-ties. J. Solid State Chem. 2018, 260, 106-116. [CrossRef]

36. Prola, L.; Machado, F.; Bergmann, C.P.; de Souza, F.E.; Gally, C.R.; Lima, E.C.; Adebayo, M.; Dias, S.; Calvete, T. Adsorption of Direct Blue 53 dye from aqueous solutions by multi-walled carbon nanotubes and activated carbon. J. Environ. Manag. 2013, 130, 166-175. [CrossRef] [PubMed]

37. Salomón, Y.L.D.O.; Georgin, J.; Reis, G.; Lima, E.C.; Oliveira, M.L.S.; Franco, D.S.P.; Netto, M.S.; Allasia, D.; Dotto, G.L. Utilization of Pacara Earpod tree (Enterolobium contortisilquum) and Ironwood (Caesalpinia leiostachya) seeds as low-cost biosorbents for removal of basic fuchsin. Environ. Sci. Pollut. Res. 2020, 27, 33307-33320. [CrossRef] [PubMed]

38. Chandra, I.K.; Ju, Y.-H.; Ayucitra, A.; Ismadji, S. Evans blue removal from wastewater by rarasaponin-bentonite. Int. J. Environ. Sci. Technol. 2012, 10, 359-370. [CrossRef]

39. Kefif, F.; Ezziane, K.; Bahmani, A.; Bettahar, N.; Mayouf, S. Evans Blue dye removal from contaminated water on calcined and uncalcined $\mathrm{Cu}-\mathrm{Al}-\mathrm{CO}_{3} \mathrm{Cu}-\mathrm{Al}-\mathrm{CO}_{3}$ layered double hydroxide materials prepared by coprecipitation. Bull. Mater. Sci. 2019, 42, 14 . [CrossRef]

40. Manjunatha, C.; Nagabhushana, B.; Raghu, M.S.; Pratibha, S.; Dhananjaya, N.; Narayana, A. Perovskite lanthanum aluminate nanoparticles applications in antimicrobial activity, adsorptive removal of Direct Blue 53 dye and fluoride. Mater. Sci. Eng. C 2019, 101, 674-685. [CrossRef]

41. Bouraada, M.; Bessaha, H.; De Ménorval, L.C. Removal of Evans Blue and Yellow thiazole dyes from aqueous solution by $\mathrm{Mg}-\mathrm{Al}-\mathrm{CO}_{3}$ Layered Double Hydroxides as anion-exchanger. Mediterr. J. Chem. 2014, 3, 894-906. [CrossRef]

42. Dos Reis, G.S.; Bin Mahbub, M.K.; Wilhelm, M.; Lima, E.C.; Sampaio, C.H.; Saucier, C.; Dias, S. Activated carbon from sewage sludge for removal of sodium diclofenac and nimesulide from aqueous solutions. Korean J. Chem. Eng. 2016, 33, $3149-3161$. [CrossRef]

43. Kasperiski, F.M.; Lima, E.C.; dos Reis, G.S.; da Costa, J.B.; Dotto, G.L.; Dias, S.L.P.; Cunha, M.R.; Pavan, F.A.; Correa, C.S. Preparation of CTAB-functionalized aqai stalk and its efficient application as adsorbent for the removal of Direct Blue 15 and Direct Red 23 dyes from aqueous media. Chem. Eng. Commun. 2018, 205, 1520-1536. [CrossRef]

44. Lima, É.C.; Adebayo, M.A.; Machado, F.M. Kinetic and Equilibrium Models of Adsorption. In Carbon Nanomaterials as Adsorbents for Environmental and Biological Applications; Springer: Cham, Switzerland, 2015; pp. 33-69.

45. Thue, P.S.; Umpierres, C.S.; Lima, E.C.; Lima, D.R.; Machado, F.M.; dos Reis, G.S.; da Silva, R.S.; Pavan, F.A.; Tran, H.N. Single-step pyrolysis for producing magnetic activated carbon from tucumã (Astrocaryum aculeatum) seed and nickel(II) chloride and zinc(II) chloride Application for removal of nicotinamide and propranolol. J. Hazard. Mater. 2020, 398, 122903. [CrossRef] [PubMed]

46. Caicedo, D.F.; dos Reis, G.S.; Lima, E.C.; De Brum, I.A.; Thue, P.S.; Cazacliu, B.G.; Lima, D.; dos Santos, A.H.; Dotto, G.L. Efficient adsorbent based on construction and demolition wastes functionalized with 3-aminopropyltriethoxysilane (APTES) for the removal ciprofloxacin from hospital synthetic effluents. J. Environ. Chem. Eng. 2020, 8, 103875. [CrossRef]

47. Lima, V.V.C.; Nora, F.B.D.; Peres, E.C.; Reis, G.S.; Lima Éder, C.; Oliveira, M.L.; Dotto, G.L. Synthesis and characterization of biopolymers functionalized with APTES (3-aminopropyltriethoxysilane) for the adsorption of sunset yellow dye. J. Environ. Chem. Eng. 2019, 7, 103410. [CrossRef]

48. dos Reis, G.S.; Larsson, S.H.; Thyrel, M.; Pham, T.N.; Claudio Lima, E.; de Oliveira, H.P.; Dotto, G.L. Preparation and Appli-cation of Efficient Biobased Carbon Adsorbents Prepared from Spruce Bark Residues for Efficient Removal of Reactive Dyes and Colors from Synthetic Effluents. Coatings 2021, 11, 772. [CrossRef] 
49. Cunha, M.R.; Lima, E.C.; Lima, D.R.; da Silva, R.S.; Thue, P.S.; Seliem, M.K.; Sher, F.; dos Reis, G.S.; Larsson, S.H. Removal of captopril pharmaceutical from synthetic pharmaceutical-industry wastewaters: Use of activated carbon derived from Bu-tia catarinensis. J. Environ. Chem. Eng. 2020, 8, 104506. [CrossRef]

50. Teixeira, R.A.; Lima, E.C.; Benetti, A.D.; Thue, P.S.; Cunha, M.R.; Cimirro, N.F.G.M.; Sher, F.; Hadi Dehghani, M.; dos Reis, G.S.; Dotto, G.L. Preparation of hybrids of wood sawdust with 3-aminopropyltriethoxysilane. Application as an adsor-bent to remove Reactive Blue 4 dye from wastewater effluents. J. Taiwan Inst. Chem. Eng. 2021, 125, 141152. [CrossRef] 